\title{
Los ferrocarriles de servicio público en Venezuela (1870-1990)
}

\author{
Antonio Santamaría García \\ Instituto Universitario Ortega y Gasset, Madrid
}

\begin{abstract}
Este artículo es un estado de la cuestión sobre la historia de los ferrocarriles de servicio público en Venezuela. El trabajo formó parte del proyecto financiado por la Fundación de los Ferrocarriles Españoles, "Los Ferrocarriles Latinoamericanos Ayer, Hoy y Mañana" (1990-92), cuyo objetivo fue construir una base de datos con la bibliografía y las fuentes, fundamentalmente estadísticas, existentes para el estudio del tema. A continuación presentamos los resultados para el caso venezolano, manteniendo como hipótesis que el desarrollo ferroviario en ese país estuvo más determinado que en el resto de América Latina por las necesidades de la construcción del Estado y de integración de la economía nacional en el mercado mundial como productora primario-exportadora. Tal fue la dependencia que aquél tuvo de estos elementos, que tras la finalización del ciclo alcista primario-exportador en las décadas de 1920-30, la explotación ferroviaria sufrió una crisis cuya solución fue el cierre de las líneas.
\end{abstract}

\section{Introducción}

A pesar de la importancia que la historiografía confiere al ferrocarril en el crecimiento económico, el estudio de este medio de transporte en América Latina ha sido poco investigado. Para paliar dicha carencia, La Fundación de los Ferrocarriles Españoles (FFE) financió entre 199092 el proyecto "Los Ferrocarriles Latinoamericanos Ayer, Hoy y Mañana". El objetivo fue elaborar un estado de la cuestión sobre el tema para cada uno de los países de la región, completándolo con la información de algunas fuentes inexplotadas, sobre todo estadísticas. ${ }^{1}$ Con ese material se construyó una base de datos que pudiera servir a futuras inves-

1 Para Venezuela contamos con seis publicaciones periódicas (Railway Directory and Yearbook, Nueva York; Jane's World Railways [JWR], Nueva York; Boletín del Congreso Panamericano de Ferrocarriles [BCPF]; ALAF: Anuario Estadístico Ferroviario Latinoamericano, Nueva York; OEA: América en cifras, Nueva York y CEPAL: Anuario Estadístico, Nueva York) y cinco informes (CEPAL: El transporte en América Latina, Nueva York, 1975; W.R. Long: Railways of South America, Washington, 1925; P.E. Bloom: "Railways of Latin America. Venezuela", Industrial Reference Service, Washington, 1946 y F.M. Halsey: The Railway of South and Central America y Railway Expansion in Latin America, Washington, 1931 [ambos]). 
tigaciones. En las siguientes páginas se presentan los resultados para el caso venezolano. ${ }^{2}$

El proyecto de la FFE estudió únicamente las líneas de servicio público universal. ${ }^{3}$ La conclusión del trabajo fue que el desarrollo ferroviario latinoamericano estuvo ligado a la construcción de los estados y a la integración de las economías en el mercado mundial como productoras de materias primas en la segunda mitad del siglo XIX. La relación sectorexterno ferrocarril fue tan estrecha que la finalización del ciclo alcista primario-exportador en el período de entreguerras, provocó una crisis que este último no pudo superar. Por lo general, la apertura de nuevas líneas se detuvo en la década de $1920,{ }^{4}$ cuando sólo un pequeño número de países había logrado formar una red amplia y relativamente integrada, gracias al tamaño y diversificación de sus economías y a su extensión geográfica. ${ }^{5}$ A la crisis del sector externo se unió también en los años veinte la competencia de nuevos medios de transporte, sobre todo de la carretera, provocando en las tres décadas siguientes dos procesos paralelos de nacionalización y cierre de los ferrocarriles.

2 El estudio histórico del ferrocarril formó parte del proyecto "Libertadores", producto de la colaboración de RENFE y las empresas ferroviarias del Cono Sur. Su objetivo fue mejorar el transporte en la zona y construir o remodelar $16.000 \mathrm{kms}$. de vías, ver SEQC, ACIE y RENFE: Proyecto Libertadores, Madrid, 1992. La base de datos no se ha abierto al público, pero se han publicados varios trabajos: A. Rodríguez: "La política ferroviaria en Brasil y la cuenca del Plata en el Siglo XIX" y J.C. Sola: "El desarrollo de la red de ferrocarriles en Guatemala: economía y territorio, 1871-1941", en M. Alcantara, A. Martínez y M. Ramos (eds.): IV Encuentro de Latinoamericanistas, Salamanca, 1995; A. Santamaría: "Los ferrocarriles de servicio público en Puerto Rico, 1870-1990", Revista Complutense de Historia de América, 20, Madrid, 1994; "Los ferrocarriles de servicio público nicaragüenses, 18701990", Anuario de Estudios Americanos, LII-1, Sevilla, 1995; "Los ferrocarriles de servicio público cubanos, 1837-1959. La doble naturaleza de la dependencia azucarera”, Revista de Indias, 204, Madrid, 1995, y "Los ferrocarriles dominicanos", Minius, 4, Orense, 1995 [en prensa]. Los resultado del proyecto se encuentran en la FFE (Madrid) y fueron presentados en una sesión especial sobre "Ferrocarriles", organizada por Grupo América de Estudios Sociales, al "I Encuentro de Jóvenes Estudiantes e Investigadores sobre Historia de América", Departamento de Historia de América, U. Complutense, Madrid, septiembre 1993.

3 Transporte de mercancías y pasajeros. Esto excluye a los tranvías y a los ferrocarriles industriales, que en algunos países fueron tan importantes o más que los de servicio público. Destaca el caso cubano, donde la extensión de las líneas azucareras (12.000 kms.) duplicó a las de servicio público (5.500 kms.). Ver Santamaría: “Los ferrocarriles de servicio público cubanos...”, pág. 487.

4 La excepción fueron algunos países de América Central, ver Santamaría: "Los ferrocarriles de servicio público nicaragüenses...", págs. 117-143.

5 Fueron los casos de Brasil, Argentina, Uruguay (estudiados por A. Rodríguez en el proyecto de la FFE), Chile (F. Polo), México (J.C. Sola) y Cuba (A. Santamaría). El resto de los países estuvieron a cargo de M.A. García (Costa Rica y Honduras), M. García (Bolivia, Panamá y Paraguay), F. Polo (Ecuador), A. Santamaría (Nicaragua, Puerto Rico, República Dominicana y Venezuela), A. Sanz (El Salvador), J. Carlos Sola (Guatemala) y B. Vitar (Colombia y Perú). 
Probablemente, el ferrocarril venezolano fue el más determinado por la construcción del Estado Nacional y las necesidades de la producción exportable. Se caracterizó por su escasa extensión, la más reducida de América Latina en relación con los kilómetros cuadrados de superficie, ${ }^{6}$ repartida entre un número relativamente grande de líneas desconectadas entre sí; por la ubicación de dichas líneas en sólo dos de las cuatro regiones geográficas del territorio; por la concentración del período de construcción en la década de $1880,{ }^{7}$ y por la superposición de dos rápidos procesos de nacionalización y cierre de las empresas en las décadas de 1940-60. El cuadro 1 ilustra lo que decimos. En 1975 prestaban servicio $177 \mathrm{kms}$. de los 967 que se tendieron. Cotejando absoluta y relativamente esa cifra con la media latinoamericana y con la de Colombia, país fronterizo y de extensión similar a la de Venezuela, la escasa implantación del ferrocarril en este último no deja lugar a dudas. La comparación no variaría sustancialmente si eligiésemos otros cortes temporales. La explicación de esos hechos requiere una introducción geográfica e histórica.

\section{CuAdro 1}

EXTENSIÓN DE LOS FERROCARRILES VENEZOLANOS, COLOMBIANOS Y LATINOAMERICANOS EN 1975 (KMS.)

País Total Porcentaje Kms./1.000 km. ${ }^{2} \mathrm{Kms} . / 1.000 \mathrm{habs.}$

$\begin{array}{lrrrr}\text { Venezuela } & 177 & 0,14 & 0,01 & 0,19 \\ \text { Colombia } & 2.800 & 2,22 & 0,12 & 2,49 \\ \text { América Latina } & 127.000 & 100,00 & 0,41 & 6,39\end{array}$

Fuente: CEPAL: El transporte..., pág. 5.

\section{El marco geográfico e histórico del ferrocarril venezolano}

El medio físico, humano y económico permiten distinguir dos grandes unidades geográficas en Venezuela. Población, ciudades, industria y agricultura comercial se concentran en la región costa-montaña (litoral y área

6 En el momento de máxima extensión sólo alcanzó 1,05kms./1.000kms² En República Dominicana, el segundo país latinoamericano donde este cociente fue más bajo, llegó a 5,2, Santamaría: "Los ferrocarriles dominicanos"..., cuadro 5.

7 En la mayoría de los países latinoamericanos el período de construcción ferroviaria comenzó en las décadas de 1870-80 y no terminó hasta las de 1920-30. 
andina), dotada, además, de ricos yacimientos de gas y petróleo. El ferrocarril nació para servir las necesidades de transporte de dicha unidad. El resto del país está ocupado por la cuenca del Orinoco. Su despoblación y las dificultades que los rápidos presentan para la navegación en el curso alto del río impidieron la formación de una red de transportes fluvial-marítimo-ferroviaria que permitiese integrar el territorio.

La economía venezolana fue predominantemente agraria hasta la década de 1930. La independencia supuso el fin del denominado ciclo del cacao al faltar el mercado comprador (España) y el inicio del ciclo cafetalero. La falta de mano de obra debido a la despoblación del país y la competencia de la producción colombiana y brasileña, empero, impidieron la formación de una base económica asentada en el cultivo del café que hiciese viable un proyecto político nacional. ${ }^{8}$ La historia política reprodujo los problemas económicos. A la emancipación siguió un período de luchas entre las elites locales y entre comerciantes y hacendados cafetaleros que desembocó en la Revolución Federal, la cual terminó en 1870 con la victoria de las fuerzas agrupadas en torno a Antonio Guzmán Blanco. ${ }^{9}$ Bajo su égida, Venezuela vivió un primer momento de relativa estabilidad y crecimiento que permitió construir los ferrocarriles. No obstante, los conflictos no se resolvieron, y en 1889 la Revolución Liberal Conservadora llevó al poder a la oligarquía del área andina, cuyo predominio se fue fraguando desde mediados del siglo XIX debido al traslado de los cafetales de los valles del centro-norte a la región oriental. El gobierno de Cipriano Castro y su continuación en la dictadura de Juan Vicente Gómez, prolongada hasta 1936, significaron la definitiva formación de un estado y una economía nacional. La autoridad de Gómez se basó en un aparato clientelístico, en la creación de un ejército profesional y en la participación en el gobierno del llamado Grupo de los Doctores, que intentó modernizar el país siguiendo los preceptos del Positivismo. Esto permitió a Gómez controlar a las elites locales y eliminar a la oposición.

La modernización económica y la relativa integración del territorio que no permitieron café y ferrocarril fue posible gracias al petróleo y la carretera. La transición de la economía cafetalera a la petrolera comenzó en el inicio del siglo XX y se consolidó con la crisis de 1930. El crecimiento de años posteriores estuvo acompañado por una mayor complejidad de la estructura socio-política. Muerto Gómez, en 1936, las clases medias y

8 G. Morón: Breve historia de Venezuela, Madrid, 1979, pág. 181.

9 Ver L. Alvarado: Historia de la Revolución Federal en Venezuela, Caracas, 1956. 
MAPA 1. GEOGRAFÍA y ECONOMÍA DE VENEZUELA

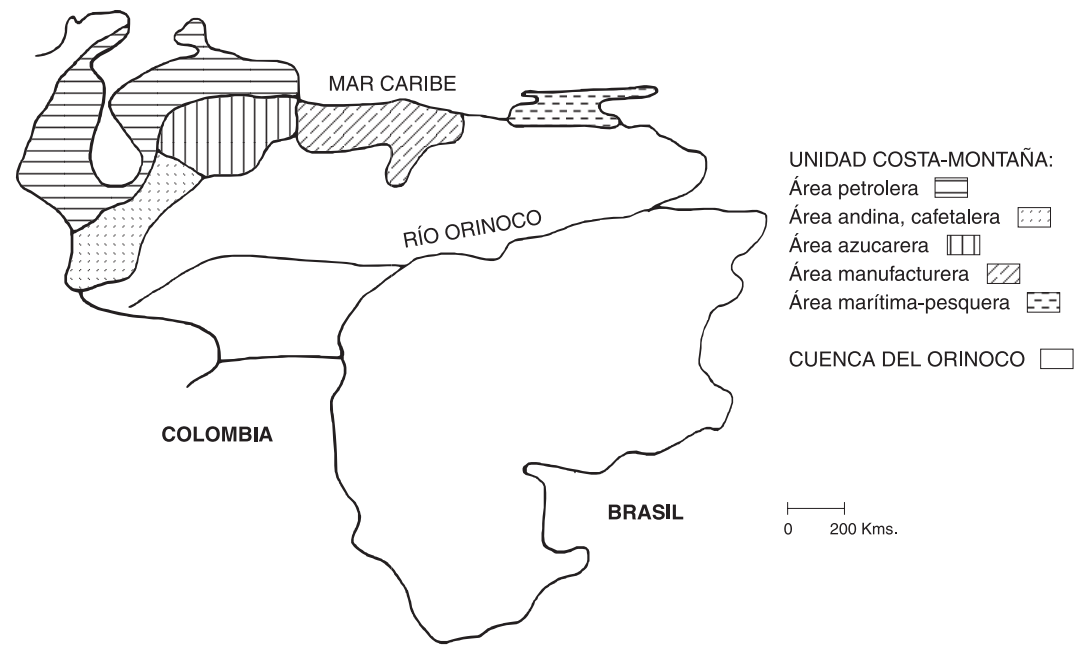

Fuente: Ramón A. Tovar, "La costa-montaña en Venezuela", en Geografía de América Latina, Barcelona, Ed. Teide, 1979, pág. 334.

\section{MAPA 2. LOS FERROCARRILES PÚBLICOS EN VENEZUELA}

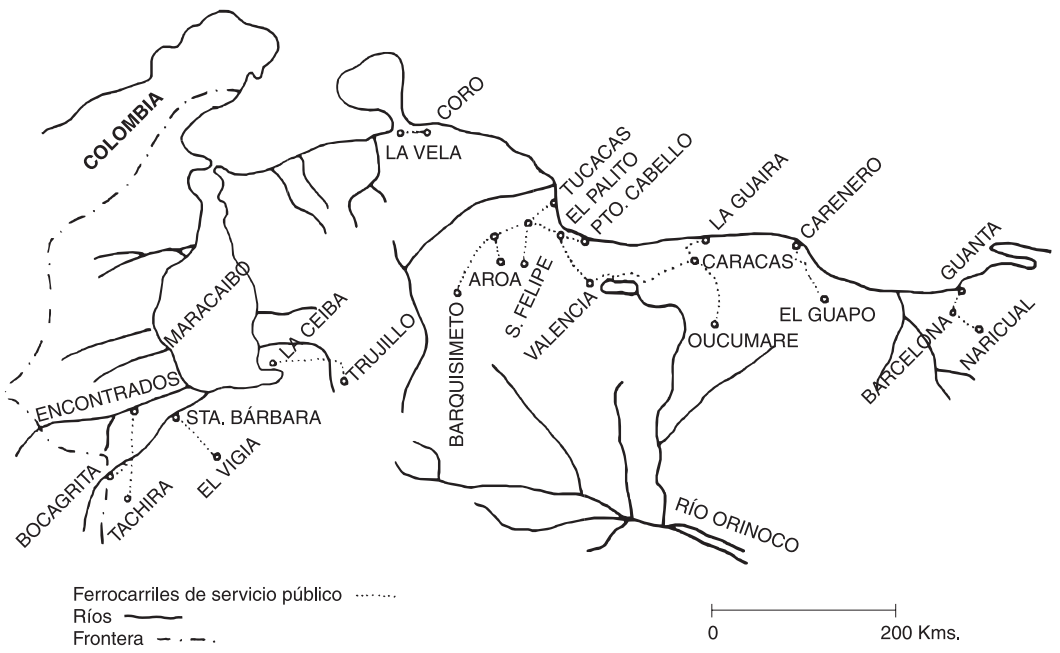

Fuente: W. R. Long, Railways..., pág. 379. 
obreras, organizadas en el Partido de Acción Democrática (AD), empezaron a demandar cambios en el sistema de dominación oligárquica, llegando al poder en 1945. El nuevo gobierno inició un proceso de intervención en la economía para proteger el incipiente desarrollo industrial y promover un reparto más equitativo de la renta, obligando a las empresas petroleras a entregar el 50\% de sus ganancias. Mientras, el aumento de la demanda interna y la protección de una industria, cuyo producto se destinaba al mercado nacional, provocaron un incremento de las importaciones, inflación y déficits crónicos de la balanza de pagos. El estrangulamiento del modelo de crecimiento y la inestabilidad política se agudizaron en las siguientes décadas, hasta entrar en crisis en los años ochenta. El proceso de liberalización económica, el control de la inflación y del gasto iniciado entonces no han dado el resultado esperado y han agravado los problemas sociales. ${ }^{10}$

\section{El marco institucional. El Estado y las empresas ferroviarias}

En Venezuela, como en toda América Latina, el interés del Estado por el ferrocarril comenzó con la independencia. El primer proyecto data de 1834. Pretendía la construcción de una red que proporcionase salida al mar a la producción y conectase entre sí los valles de la región centro-norte. No obstante, y a pesar de los múltiples contratos y de la construcción de algunos tramos de vía, la primera línea no pudo ser inaugurada hasta 1877, debido a la inestabilidad política y económica; después de ese año hubo que esperar más de un lustro para el inicio del período de expansión ferroviaria.

Fue en los años ochenta cuando coadyuvaron los factores precisos para la construcción ferroviaria. La crisis de 1873 supuso la reestructuración del sistema económico internacional y el inicio del ciclo alcista de la producción primario-exportadora, con el que los países latinoamericanos se integraron en el mercado mundial. Es muy significativo que casi todas las líneas venezolanas conectasen centros económicos del interior con sus puertos más cercanos. Unido a este hecho se encuentra el comienzo de la consolidación del sistema económico y del Estado nacional, cuyo exponente político - como dijimos - fue Guzmán Blanco. El tercer factor fue el inicio de una larga fase de crecimiento económico internacional, que liberó el flujo de capital necesario para financiar la construcción de infra-

10 Ver CEPAL: La industrialización en América Latina, Nueva York, 1965. 
estructura y la explotación de los recursos de los países nuevos. Todo estado con estabilidad suficiente, capacidad política para ofrecer las garantías imprescindibles y cierta credibilidad exterior pudo aprovechar dicho flujo. El ferrocarril fue pieza clave en el sistema que se estaba configurando: atrajo capital, desarrolló las zonas que atravesó, aumentó la competividad de los productos transportados y tuvo efectos multiplicadores en la oferta y la demanda y tanto hacia el interior como hacia el exterior, pues requirió importar bienes y tecnología de los países en los que se originó el flujo de capital que permitió su construcción. En suma, fue capaz de cerrar el ciclo económico en que se integró. En cuanto a su papel como medio de transporte, la dicotomía ferrocarril-carretera que definió la historia de las comunicaciones en Venezuela, al menos hasta 1910, no se resolvió en entente. ${ }^{11}$ Una red de caminos inadecuada para las necesidades económicas no pudo competir con el tren, y los recursos destinados a ella fueron transferidos a él. Aparte de esa decisión de carácter general, la política ferroviaria se distinguió por su liberalismo, concretado en los elementos que definieron las concesiones otorgadas por Guzmán Blanco: cesión durante 99 años, entrega de terrenos a ambos lados de la vía, exención de impuestos y de derechos de importación, liberalidad casi ilimitada en la explotación y garantía del 7\% sobre el capital invertido, medida fijada por ley en $1883 .{ }^{12}$ Nada se hizo por fomentar el desarrollo industrial, por regular la coordinación de las líneas o su distribución por el territorio. No obstante, no se debe juzgar esa actitud fuera de sus circunstancias históricas. La política ferroviaria fue la más lógica y común en su momento, y además el gobierno carecía de fuerza económica y política para ejercer un control mayor. ${ }^{13}$

La clave para entender la política ferroviaria venezolana es la citada garantía del 7\%. Entre 1889-99 se otorgaron 31 concesiones, pero sólo se construyó un 20\% de lo concedido. ${ }^{14}$ Entre 1883-95 se abrieron al tráfico 728 kms., el 80\% del kilometraje con que llegaron a contar las líneas se servicio público (cuadro 6). El paroxismo de las concesiones, la falta de regu-

11 Ver Ministerio de Obras Públicas de Venezuela (MOP): Centenario del MOP de Venezuela, 1874-1974, Caracas, 1974, págs. 53 y 126.

12 Arcila, E.: Historia de la ingeniería en Venezuela, Caracas, 1961, pág. 168.

13 En estas conclusiones coincidieron la mayor parte de las investigaciones del proyecto de la FFE para otros países latinoamericanos.

14 Los cuadros del texto en que no se hacen explícitas las fuentes han sido elaborados utilizando la información dispersa en la bibliografía y documentación consultadas para realizar la investigación. Es preciso señalar, asimismo, que un grupo de personas trabajó expresamente en el proyecto de la FFE reconstruyendo series estadísticas. Reconocer esa labor no nos exime de la responsabilidad por cualquier defecto en los datos presentados en el artículo. 
lación y de beneficios fiscales producto del desarrollo económico que el ferrocarril debía impulsar, colocaron al país al borde de la bancarrota, mientras las compañías exigían el pago de los intereses devengados de la garantía. ${ }^{15}$ Esa situación llevó a Joaquín Crespo, sucesor de Guzmán Blanco, a cambiar de política. Una ley de 1892 prohibió otorgar concesiones a empresas que no estuviesen debidamente constituidas, para evitar los perjuicios que en el pasado causaron los contratos que no contaron con la solvencia de éstas y la acción de especuladores, que se hicieron con los mismos para revenderlos y obtener rápidas ganancias. En segundo lugar, entendiendo que lo elevado de las tarifas había sido la causa de que el ferrocarril no arrojase las utilidades esperadas, la ley estipuló que serían fijadas por el gobierno. No obstante, éstas siguieron siendo altas debido a la escasa longitud de las líneas y a la ausencia de conexión entre ellas. ${ }^{16}$ Intentando solucionar ese problema, en tercer lugar, se ordenó que el ancho de las vías construidas a partir de 1892 fuese de 1,067 ms. Sin embargo, la medida no fue eficaz, pues casi toda la infraestructura viaria estaba construida en ese año. Finalmente, para obligar a las empresas a cumplir los contratos, se reafirmó la concesión de tierras a ambos lados de la vía, pero condicionándola a la finalización de los tramos pactados.

A pesar del mayor control del gobierno, la ley de 1892 permitió a las empresas seguir operando con suma libertad. La única disposición transcendente fue la supresión de la garantía del 7\%. En cambio, estipuló que las compañías debían entregar al Estado un 5\% de sus ganancias netas. ${ }^{17} \mathrm{La}$ medida solucionó, en parte, el conflicto Estado-ferrocarril debido al impago de las obligaciones contraídas por aquél, que en 1886 sumaban 25.000.000 de bolívares. ${ }^{18}$ En ese año, el Diskonto Gesellschaft alemán concedió un préstamo de 50.000 .000 bols. al gobierno para saldar dicha deuda y rescatar la garantía. Sin embargo, el problema no se solucionó, pues el pago del empréstito fue causa de constantes reclamaciones exteriores y ni siquiera permitió eliminar completamente la deuda ferroviaria, ya que el ferrocarril Puerto Cabello-Valencia se negó a negociarla. Hasta el acuerdo firmado en 1916, éste continuó gozando de una garantía del $5 \% .^{19}$

\footnotetext{
15 Jahn, A.: Desarrollo de las vías de comunicación en Venezuela, Caracas, 1975, pág. 19.

16 Bloom: "Railways...", pág. 156.

17 Para más detalles sobre estas leyes, ver MOP: Centenario..., págs. 162-64.

18 Jahn: Desarrollo..., pág. 19.

19 MOP: Centenario..., págs. 166-67 y Jahn: Desarrollo..., pág. 19.
} 


\section{CUADRO 2}

CONCESIONES PARA LA CONSTRUCCIÓN, AMPLIACIÓN Y TRASPASO DE FERROCARRILES Y EMPRESAS FERROVIARIAS DE SERVICIO PÚBLICO EN VENEZUELA, 1834-1957

\begin{tabular}{|c|c|c|c|c|c|c|c|c|}
\hline \multirow[b]{2}{*}{ Años } & \multicolumn{3}{|c|}{ Concesión } & \multicolumn{2}{|l|}{ Receptor } & \multicolumn{3}{|c|}{ Kilómetros + } \\
\hline & Trazado & Ferroc. & Tipo@ & Nombre & Nacio. \# & 1 & 2 & Año \\
\hline 1834 & La Guaira-Pto. Cabello & Central * & $\mathrm{CO}$ & $\mathrm{HGP}++$ & Gran B. & 270 & 0 & - \\
\hline 1835 & Tucacas-Aroa & Bolívar & $\mathrm{CO}$ & - & - & 68 & 0 & - \\
\hline 1854 & La Guaira-Pto. Cabello & Central * & $\mathrm{CO}$ & - & - & 270 & 0 & - \\
\hline 1856 & La Guaira-Pto. Cabello & Central * & $\mathrm{CO}$ & - & - & 270 & 0 & - \\
\hline 1867 & La Guaira-Pto. Cabello & Central * & $\mathrm{CO}$ & Bruznal y Nugent & Venez. & 270 & 0 & - \\
\hline 1874 & La Guaira-Pto. Cabello & Central * & $\mathrm{CO}$ & $\mathrm{OL}++$ & Gran B. & 270 & 0 & - \\
\hline \multirow[t]{2}{*}{1876} & La Guaira-Pto. Cabello & Central * & $\mathrm{CO}$ & J. Antommarchi & Francia & 270 & 0 & - \\
\hline & S. Felipe-Barquisimeto & Ídem & $\mathrm{CO}$ & S. Viqle & Venez. & 109 & 0 & - \\
\hline \multirow[t]{2}{*}{1877} & Tucacas-Aroa & Bolívar & $\mathrm{CO}$ & New Quebrada & Gran B. & 68 & 68 & 1877 \\
\hline & La Guaira-Macuto ** & Ídem & $\mathrm{C}$ & Junta Fom & Venez. & 8 & 8 & 1885 \\
\hline \multirow[t]{2}{*}{1880} & La Ceiba-Sab. Mendoza & La Ceiba & $\mathrm{CO}$ & B. Roncájolo & $\mathrm{F} / \mathrm{V}$ & 81 & 81 & 1888 \\
\hline & La Guaira-Pto. Cabello & Central * & $\mathrm{CO}$ & W.A. Pile & USA & 270 & 0 & - \\
\hline \multirow[t]{2}{*}{1881} & La Guaira-Caracas & Ídem & $\mathrm{T}$ & W.C. Quilter & Gran B. & 37 & 37 & 1883 \\
\hline & S. Felipe-Barquisimeto & Ídem & $\mathrm{CO}$ & S. Viale & & 109 & 0 & - \\
\hline \multirow[t]{2}{*}{1882} & Caracas-Antimano & Antimano & $\mathrm{CO}$ & $\mathrm{RH}++$ & & - & 4 & 1886 \\
\hline & Pto. Cabello-Valencia & Ídem & $\mathrm{CO}$ & W.A. Pile & & 55 & 0 & - \\
\hline \multirow[t]{3}{*}{1883} & Pto. Cabello-Valencias & Ídem & $\mathrm{C}$ & Junta Fomen & & 55 & - & 1885 \\
\hline & La Guaira-Ca & Ídem & $\mathrm{C}$ & Junta Fomento & & 37 & - & 1883 \\
\hline & eto-El Hacha & Bolívar & $\mathrm{AL}$ & Quebrada Rw. & Gral & 87 & 0 & - \\
\hline \multirow[t]{2}{*}{1884} & Suapo & Carenero & $\mathrm{CO}$ & L. Puig & Ven & 54 & - & - \\
\hline & Caren & Carer & $\mathrm{T}$ & Carenero Rw. & & 54 & 54 & 1889 \\
\hline \multirow[t]{6}{*}{1885} & & & & & & 220 & 40 & 1892 \\
\hline & Guanta-Naricual & Naricual & $\mathrm{CO}$ & GBNR ++ & Gran B. & 37 & 37 & 1893 \\
\hline & Sta. Bárbara-El Vigía & Ídem & $\mathrm{CO}$ & Duque de Monry & & 60 & 0 & - \\
\hline & Pto. Cabello-Valencia & Ídem & $\mathrm{CO}$ & $\mathrm{CL}++$ & Gran B. & 55 & 55 & 1890 \\
\hline & La Guaira-Macuto & Ídem & $\mathrm{P}$ & - & Venez. & 8 & 0 & - \\
\hline & Trujillo-Sab. Mendoza & La Ceiba & $\mathrm{AL}$ & B. Roncáj & & 一 & - & - \\
\hline 1886 & s-Antimano & Antimano & $\mathrm{T}$ & Junta $F$ & & 8 & 4 & 1886 \\
\hline \multirow[t]{2}{*}{1887} & Cara & Antimano & $\mathrm{P}$ & L.A. Müller & & 8 & 0 & - \\
\hline & & Antimano & $\mathrm{O} \quad \mathrm{P}$ & Gran Fc. & & 8 & 0 & - \\
\hline \multirow[t]{3}{*}{1888} & Antimano-Valencia & Gran Fc. & $\mathrm{CO}$ & L.A. Müller & Aleman. & 171 & 171 & 1893 \\
\hline & Altagracia-Mar Caribe & Carenero & $\mathrm{CO}$ & J. Barris & Francia & - & 0 & - \\
\hline & Altagracia-Mar Caribe & Carenero & $\mathrm{CO}$ & Carenero Rw. & - & - & 0 & - \\
\hline \multirow[t]{2}{*}{1890} & Caracas-Valencia & Gran Fc. & $\mathrm{RC}$ & & Aleman. & 179 & 0 & - \\
\hline & Arenaza-Sta. Lucía & Central & $\mathrm{AL}$ & Venezuela Ctral. & Gran B. & 15 & 0 & - \\
\hline 1891 & Sta. Bárbara-El Vigía & Ídem & $\mathrm{CO}$ & C. Weber & - & 60 & 60 & 1891 \\
\hline 1892 & La Vela-Coro & Ídem & $\mathrm{CO}$ & M. Capriles & USA & 14 & 14 & 1897 \\
\hline 1892 & Encontrados-La Fría & Táchira & $\mathrm{CO}$ & Roncájolo ++ & $\mathrm{V} / \mathrm{F}$ & 105 & 0 & - \\
\hline 1893 & Encontrados-La Fría & Táchira & $\mathrm{CO}$ & Roncájolo ++ & Venez. & 105 & 105 & 1895 \\
\hline 1895 & La Ceiba-Trujillo & La Ceiba & $\mathrm{AL}$ & Gran Fc. Ceiba & Venez. & 74 & 0 & - \\
\hline 1896 & Arenaza-Sta. Lucía & Central & $\mathrm{AL}$ & Venezuela Ctral. & Gran B. & 15 & 0 & - \\
\hline
\end{tabular}




\section{CUADRO 2 (continuación)}

\begin{tabular}{|c|c|c|c|c|c|c|c|c|}
\hline \multirow[b]{2}{*}{ Años } & \multicolumn{3}{|c|}{ Concesión } & \multicolumn{2}{|l|}{ Receptor } & \multicolumn{3}{|c|}{ Kilómetros + } \\
\hline & Trazado & Ferroc. & Tipo@ & Nombre & Nacio. \# & 1 & 2 & $A \tilde{n} o$ \\
\hline 1897 & Encontrados-La Fría & Táchira & $\mathrm{T}$ & Gran Fc. Táchira & Venez. & 105 & 0 & \\
\hline 1898 & La Fría-Uraca & Táchira & $\mathrm{AL}$ & Gran Fc. Táchira & Venez. & 9 & 9 & 1899 \\
\hline 1899 & Carenero-El Guapo & Carenero & $\mathrm{T}$ & V. Cassaus & $\mathrm{V} / \mathrm{F}$ & 54 & 0 & \\
\hline 1905 & Arenaza-Sta. Lucía & Gran Fc. & $\mathrm{AL}$ & Venezuela Ctral. & Gran B. & 15 & 5 & 1911 \\
\hline 1907 & La Vela-Coro & Ídem & $\mathrm{T}$ & - & USA & 14 & 0 & - \\
\hline 1909 & Sta. Bárbara-El Vigía & Ídem & A & - & - & 60 & 0 & - \\
\hline 1910 & Tucacas-Barquisimeto & Bolívar & $\mathrm{RC}$ & Quebrada Rw. & Gran B. & 177 & & - \\
\hline \multirow[t]{2}{*}{1912} & La Guaira-Macuto & Ídem & $\mathrm{T}$ & La Guaira Harvor & Gran B. & 8 & 0 & \\
\hline & Agua Maíz-Los Chorros & Central & $\mathrm{AL}$ & tela Ctral. & Gran B. & 3 & 3 & 1912 \\
\hline \multirow[t]{3}{*}{1913} & S. Felipe-Palmasola & Bolívar & AL & ada Rw. & Gran B. & 22 & 2 & 1913 \\
\hline & Uraca-Tác & Tách & $\mathrm{AL}$ & Fc. Táchira & Venez. & 6 & 6 & 1913 \\
\hline & Sta. Lucía & Cent & $\mathrm{AL}$ & uela Ctral. & Gran B. & 5 & 5 & 1913 \\
\hline 1922 & Sta. $\mathrm{T}$ & Central & $\mathrm{AL}$ & Vene & Gra & 22 & 3 & 1922 \\
\hline \multirow[t]{4}{*}{1924} & Pto. Cabello-Valencia & Ídem & $\mathrm{T}$ & Quebrada Rw. & Gran B. & 55 & 0 & - \\
\hline & Caracas-Valencia & Gran Fc. & $\mathrm{T}$ & FFCC Sudamers. & España & 179 & 0 & - \\
\hline & Extensión hasta Varela & La Ceiba & $\mathrm{AL}$ & & Venez. & 7 & 7 & 1925 \\
\hline & Orope-Bocagrita & Táchira & AL & Gran Fc. Táchira & Venez. & 13 & 3 & 1926 \\
\hline 1938 & El Palito-Palmasola & Ídem & $\mathrm{CO}$ & Estado & Venez. & 55 & 55 & 1942 \\
\hline 1942 & El Palito-Palmasola & Ídem & A & Quebrada Rw. & Gran B. & 55 & 0 & - \\
\hline 1944 & Red Nacion & Nacional & $\mathrm{T}$ & IAAFE & Vene & 288 & 0 & - \\
\hline 1950 & Red Nacional & Nacional & $\mathrm{AL}$ & IAAFE & Venez. & - & 0 & - \\
\hline 1957 & Red Nacional & Nacional & $\mathrm{CO}$ & IAAFE ++ & Venez. & 4250 & 177 & 1959 \\
\hline 1963 & Red Nacional & Nacional & $\mathrm{AL}$ & IAAFE & Venez. & - & 0 & . \\
\hline
\end{tabular}

++ HGP: Harring, Graham \& Powels; OL: Osbaldeston y Lyster; RH: Rivas \& Hernández; CL: Cutbill y de Lungo; Roncájolo: J. y A. Roncájolo; IAAFE: Instituto Autónomo de Administración de los Ferrocarriles del Estado.

@ C: Construcción; O: Operación; T: Traspaso de la concesión; AL: Ampliación de línea; T: Traspaso de explotación; A: Arrendamiento; P: Privatización; RC: Renovación del contrato.

+ 1: Kilómetros concedidos; 2: Kilómetros construidos; Años: año de finalización de las obras.

* El proyecto no llegó a completarse y se dividió en varias líneas independientes.

** Fue concebido como ferrocarril de transporte universal. Finalmente se dedicó sólo al de pasajeros. \# Nacio.: Nacionalidad. V/F franco-venezolana.

Con la supresión de la garantía desapareció el interés del capital extranjero por el ferrocarril. Desde 1892 su participación se redujo a la terminación de los proyectos ya iniciados. De hecho, a partir de 1893 sólo se abrieron tres nuevas líneas: la de Trujillo, la de Táchira y El PalitoPalmasola. En las tres, el capital nacional fue predominante. Además, las dos primeras estaban situadas en la región andina, donde la expansión ferroviaria fue más tardía. Recordemos que la transición del centro agrario cafetalero se desplazó hacia esa zona a finales del siglo XIX. 


\section{CuAdro 3}

FICHERO DE EMPRESAS FERROVIARIAS DE SERVICIO PÚBLICO VENEZOLANAS

\begin{tabular}{|c|c|c|c|c|c|c|c|c|c|c|}
\hline$E L T$ & Ferrocarril & $A \tilde{n} o 1-A \tilde{n} o 2$ & Kms. & Anc. & $T P$ & Nac. & Fus. & $E F$ & Cie. & $O$ \\
\hline 01100 & P. CABELLO-VALENCIA & $1890-1890$ & 55 & 1,06 & U P & & 1924 & 05 & 1957 & 1 \\
\hline 02100 & EL PALITO-P. CABELLO & - & 4 & 1,06 & U P & & - & - & & 2 \\
\hline 03100 & LA GUAIRA-CARACAS & $1883-1883$ & 37 & 0,91 & U P & 1944 & & 08 & 1951 & \\
\hline 04100 & CARENERO & 1889-1889 & 54 & 0,91 & U P & & & & 1954 & \\
\hline 05100 & BOLÍVAR & $1877-1891$ & 177 & 1,43 & $\mathrm{UP}$ & & & & & 3 \\
\hline 05101 & T Tucacas-Aroa & $1877-1877$ & 68 & 1,00 & $\mathrm{UP}$ & & & & & \\
\hline 05102 & T Barquisimeto-El Hacha & $1891-1891$ & 87 & 1,43 & U P & & & & & 4 \\
\hline 05103 & T S. Felipe-Palmasola & $1916-1916$ & 22 & 1,43 & $\mathrm{UP}$ & & & & & \\
\hline 06100 & EL PALITO-PALMASOLA & $1942-1942$ & 55 & 1,06 & U E & & & & 1957 & 5 \\
\hline 07100 & ANTIMANO & $1886-1886$ & 8 & 1,06 & U E & & 1887 & 08 & & 6 \\
\hline 08100 & GRAN FC. VENEZUELA & $1891-1893$ & 179 & 1,06 & $\mathrm{UP}$ & 1945 & & 17 & 1966 & 7 \\
\hline 08101 & T Caracas-Los Teques & $1891-1891$ & - & 1,06 & U P & & & & & \\
\hline 08102 & T Los Teques-El Corazal & $1891-1891$ & 3 & 1,06 & U P & & & & & \\
\hline 08103 & T El Corazal-El Consejo & $1891-1891$ & - & 1,06 & U P & & & & & \\
\hline 08104 & T El Consejo-Victoria & $1893-1893$ & - & 1,06 & U P & & & & & \\
\hline 08105 & T Victoria-Valencia & $1893-1893$ & - & 1,06 & $\mathrm{UP}$ & & & & & \\
\hline 08106 & $\mathrm{R}$ de Guigue & & 5 & 1,06 & $\mathrm{UP}$ & & & & & \\
\hline 09100 & GUANTA-NARICUAL & $1893-1893$ & 37 & 1,43 & $\mathrm{U} M$ & 1896 & & 17 & & 8 \\
\hline 10100 & CENTRAL DE VENEZUELA & $1886-1922$ & 86 & 1,06 & $\mathrm{UP}$ & 1938 & & 17 & 1954 & \\
\hline 10101 & T Caracas-Perate & $1886-1886$ & 10 & 1,06 & $\mathrm{UP}$ & & & & & \\
\hline 10102 & T Perate-El Encantado & $1888-1888$ & 7 & 1,06 & U P & & & & & \\
\hline 10103 & T El Encantado-La Lira & $1890-1890$ & 5 & 1,06 & $\mathrm{UP}$ & & & & & \\
\hline 10104 & T La Lira-La Envidia & $1891-1891$ & 11 & 1,06 & $\mathrm{UP}$ & & & & & \\
\hline 10105 & T La Envidia-Los Mangos & $1891-1891$ & 4 & 1,06 & U P & & & & & \\
\hline 10106 & T Los Mangos-Arenaza & $1892-1892$ & 4 & 1,06 & $\mathrm{UP}$ & & & & & \\
\hline 10107 & T Arenaza-Santa Lucía & 1911-1911 & 15 & 1,06 & $\mathrm{UP}$ & & & & & \\
\hline 10108 & T Santa Lucía-Santa Teresa & $1913-1913$ & 5 & 1,06 & $\mathrm{UP}$ & & & & & \\
\hline 10109 & T Santa Teresa-Ocumare & $1922-1922$ & 23 & 1,06 & $\mathrm{UP}$ & & & & & \\
\hline 10110 & R Agua Maíz-Chorros & 1912-1912 & 3 & 1,06 & $\mathrm{UP}$ & & & & & \\
\hline 11100 & SANTA BÁRBARA-EL VIGÍA & 1891-1891 & 60 & 1,06 & $\mathrm{U} \mathrm{M}$ & 1908 & & 17 & 1954 & 9 \\
\hline 12100 & LA VELA-CORO & 1897-1897 & 14 & 0,91 & $\mathrm{U} \mathrm{M}$ & 1909 & & 17 & & 10 \\
\hline 13100 & GRAN FC. DE LA CEIBA & $1888-1895$ & 81 & 0,91 & $\mathrm{UP}$ & & & & 1947 & \\
\hline 13101 & T Motatán-Varela & $1925-1925$ & 8 & 0,91 & U P & & & & & \\
\hline 14100 & LA CEIBA & $1888-1888$ & - & 0,91 & UP & & 1895 & 13 & & 11 \\
\hline 14102 & R de La Ceiba & $1888-1888$ & 4 & 0,91 & $\mathrm{UP}$ & & & & & \\
\hline 15100 & TRUJILLO & $1895-1895$ & - & 0,91 & U P & & 1895 & 13 & & \\
\hline 16100 & GRAN FC. DE TÁCHIRA & $1895-1913$ & 133 & 1,06 & $\mathrm{UP}$ & 1946 & & 17 & 1966 & \\
\hline 16101 & T Encontrados-La Fría & $1895-1895$ & 105 & 1,06 & U P & & & & & \\
\hline 16102 & T La Fría-Uraca & $1898-1898$ & 9 & 1.06 & $\mathrm{UP}$ & & & & & \\
\hline 16103 & T Uraca-Táchira & $1913-1913$ & 6 & 1,06 & U P & & & & & \\
\hline 16104 & E Orope-Bocagrita & $1926-1926$ & 13 & 1,06 & U P & & & & & \\
\hline 17100 & NACIONALES & $1896-1959$ & $*$ & $* *$ & $\mathrm{UE}$ & & & & & 12 \\
\hline
\end{tabular}


Abreviaturas: T: Tramo; $R$ : ramal; E: empalme: E L T: Empresa, Línea, Tramo; Año1 Año2: años de apertura del primer y último tramo; $T P$ : tipo de transporte ( $U$ : universal; $M$ : mercancías) y propiedad ( $P$ : privada; $E$ : pública); Nac. Fus.: año de nacionalización y año de fusión: $E F$ : empresa a la que se fusiona; $C i e$ : año de cierre de la línea; $O$ : observaciones.

Observaciones:

1 1959: opera como parte del Barquisimeto-Puerto Cabello.

2 Probablemente pasó a formar parte del Puerto Cabello-Valencia.

3 1924: incorporada al Puerto Cabello-Valencia. 1959: reabierto el tramo BarquisimetoPalmasola como parte del Barquisimeto-Puerto Cabello.

4 Tras su apertura, el tramo El Hacha-Aroa se convirtió en un ramal. 1959: forma parte del Barquisimeto-Puerto Cabello.

5 Nacional. Une las terminales del Bolívar y el Puerto Cabello-Valencia. 1942: El Bolívar arrendó su explotación. 1947: pasó a la administración estatal. 1959: opera como parte del Barquisimeto-Puerto Cabello.

6 El Estado inició su construcción y lo privatizó en 1887 como parte de la concesión del Gran Fc. de Venezuela, que lo abrió al tráfico con los primeros tramos de su línea en 1890.

7 Construido por la Grosse Venezuela Eichbahn-Gesellschaft. 1924: comprado por la Cía. FFCC Sudamericanos.

8 Empresa Nacional de Minas de Carbón, Ferrocarril y Muelle de Guanta. Construido por la Guanta, Barcelona \& National Rw. Co. Vendida luego al Estado. Prestó servicio de pasajeros y mercancías sólo hasta Barcelona. Desconocemos la fecha de cierre. En los años cincuenta se reconstruyó y fue reabierta al tráfico para el transporte minero.

9 Nacional. Arrendado a empresas privadas hasta 1938, año en que pasó a la administración estatal.

10 Construida por la iniciativa privada, en 1908 pasó al Estado.

11 Ignoramos la extensión y las fechas de construcción exactas.

12 Hasta 1944 consideramos arbitrariamente la existencia de una empresa que administró las líneas nacionales. 1946: Se creó el IAAFE. Desde 1959 el Barquisimeto-Puerto Cabello es el único ferrocarril de servicio público abierto en Venezuela.

La intervención directa del Estado en la construcción ferroviaria durante el siglo XIX se limitó al fomento inicial de algunas líneas: la de Antimano, Puerto Cabello-Valencia y La Guaira-Macuto (concebida como ampliación del ferrocarril La Guaira-Puerto Cabello y dedicado luego al transporte de viajeros). El primero fue entregado como parte de la concesión otorgada al Gran Ferrocarril de Venezuela, los otros dos privatizados. ${ }^{20}$ En cuanto a la intervención estatal en la explotación de las líneas, estuvo relacionada con las peculiaridades de la política de transportes y con el asunto de la garantía. No es casual que en los cuatro casos en que se produjo antes de 1930, fuera en los tendidos construidos en la década de 1990, situados fuera de la región centro-norte del país.

20 Sobre estos tres ferrocarriles, ver Arcila: Historia..., págs. 185-202 y 220-35; Long: Railways..., págs. 181 y 388-90 y Bloom: "Railways...”, pág. 151. 
En la región andina, al sur del Maracaibo, comenzó a levantarse en 1891 el trazado Santa Bárbara-El Vigía. Dificultades técnicas y financieras obligaron a los concesionarios a abandonar la explotación. En 1908 el Estado se hizo cargo de él, teniendo que reconstruirlo para volver a ponerlo en operación. Aunque fue el único medio de transporte para exportar la producción agraria del valle de Mérida, continuó siendo una empresa deficitaria. El Estado no se hizo cargo directamente de su administración, sino que la cedió en arrendamiento hasta 1937, año en que decidió nacionalizarla. Finalmente, en 1957 fue cerrado al tráfico. ${ }^{21}$

El caso del Gran Ferrocarril de Táchira es muy peculiar. Por su tardía fecha de construcción no gozó del apoyo fiscal y tuvo que entregar al Estado el 5\% de sus ganancias. ${ }^{22}$ Esas dificultades obligaron a los concesionarios, los hermanos Roncájolo, a adquirir una deuda, cuyas acciones cambiaron sucesivamente de manos hasta acabar en poder del Estado en 1936. Esta línea se concibió para sacar al mar la producción del valle de Táchira, lo que hasta ese momento se hacía a través de Colombia. Intentando absorber el tráfico fronterizo, abrió en 1926 el empalme OropeBocagrita con el ferrocarril de Cúcuta (Colombia), la única conexión internacional de los ferrocarriles venezolanos. Tratando de monopolizar el transporte en la zona, la empresa ferroviaria compró en 1933 la Flota del Lago, que ofrecía un servicio de navegación entre la terminal del tren en el río Encontrados y el Maracaibo. Esa decisión fue su ruina, pues la desembocadura del río se anegaba periódicamente y el Estado, que no se hizo cargo de la compañía, pero era el accionista mayoritario, obstaculizó reiteradamente su drenaje. Para entonces, la decisión de construir la carretera central de Táchira, tomada en 1911, atraía toda la atención del gobierno. Finalmente, la línea se nacionalizó en 1946 y, a pesar de esos inconvenientes, continuó operando hasta 1966.23

La tercera línea en cuya administración intervino directamente el Estado fue la de La Vela-Coro. Línea peculiar por su escaso recorrido y por estar situada en el Noroeste del país, lejos de las zonas de expansión ferro-

21 Bloom: "Railways...”, pág. 153; Long: Railways..., pág. 346; Arcila: Historia.., pág. 263; $B C P F$, ene.-feb. 1948, pág. 122 y L. Baez: "Recientes disposiciones dictadas en Venezuela para la explotación de los ferrocarriles nacionales", Actas del Congreso Panamericano de Ferrocarriles, Montevideo, 1946, pág. 451.

22 Noguera, J. A.: Historia del Gran Ferrocarril de Táchira, Caracas, 1965, págs. 5-8.

23 Ibídem; Arcila: Historia..., pág. 253; MOP: Centenario..., pág. 187; BCPF, may.-jun. 1945, pág. 80; Bloom: “Railways...”, págs. 151-52 y Long: Railways..., pág. 352. 
viaria. Su tardía construcción (1897) le impidió gozar también de apoyo fiscal, y enseguida comenzó a arrojar pérdidas. En 1907 quebró la empresa concesionaria. Un sindicato norteamericano se hizo cargo de la misma y saldó sus deudas, y en 1909 pasó a manos del Estado. Aunque en principio pensó arrendarla, debido a su corto recorrido, y a pesar de que los resultados económicos mejoraron sensiblemente, permaneció bajo la dirección estatal. Ignoramos la fecha exacta, pero posiblemente se cerró al tráfico a mediados de la década de $1950 .{ }^{24}$

El caso del ferrocarril Naricual es también peculiar. La línea de servicio público más oriental de Venezuela tuvo como razón de ser el transporte minero. De hecho sólo el tramo Guanta-Barcelona se dedicó al servicio público. Su construcción (1885-93) estuvo a cargo de capitales nacionales, los cuales decidieron venderlo al Estado en 1896, quien lo administró desde entonces. A principios de la década de 1950 se cerró al tráfico para ser remodelado. Más tarde se volvió a poner en explotación sólo para el transporte minero. ${ }^{25}$

Aunque la política ferroviaria no experimentó grandes cambios hasta la década de 1930, a partir de 1910 encontramos algunos antecedentes de lo que posteriormente fue un plan de actuación más amplio en materia de transportes. Dicho plan, al contrario de lo que sucedió a finales del siglo XIX, favoreció a la carretera. ${ }^{26} \mathrm{La}$ red de carreteras se concibió de forma muy distinta a la ferroviaria. Hablar de la existencia de una red no es en este caso tan eufemístico. Completando las arterias naturales, se tendieron rutas a lo largo de la costa, entre ésta y el curso del Orinoco y desde el delta del río hasta el sur del Maracaibo. Además, el ferrocarril contó con inconvenientes añadidos. En primer lugar, sólo es competitivo frente a los automóviles en largas distancias, de forma que se vio perjudicado por la escasa longitud de los trazados y lo elevado de las tarifas. Anchos de vía y terminales diferentes, ${ }^{27}$ incluso dentro de las mismas ciudades, impidieron la

24 Como peculiaridad, debemos señalar que fue uno de los pocos ferrocarriles venezolanos en los que invirtió el capital norteamericano y, concretamente, el único construido directamente por él. Sobre esta línea, ver Arcila: Historia..., pág. 264; Long: Railways..., pág. 344 y Bloom: "Railways...", pág. 153.

25 Ver Long: Railways..., pág. 342; Bloom: "Railways...”, pág. 154; Arcila: Historia..., págs. 256-61; $B C P F$, may.-jun. 1945, pág. 80 y Banco Interamericano de Desarrollo (BID): El desarrollo económico de Venezuela, 1975, pág. 330.

26 La decisión oficial se consumó en un decreto publicado en esa fecha, con el que nacieron las Carreteras Centrales. Ver MOP: Centenario..., págs. 209-16.

27 "Sinopsis de los ferrocarriles de Venezuela", $B C P F$, abr.-may. 1972, pág. 61. 
coordinación de las líneas, agravando los problemas anteriores, y más difícil todavía fue la coordinación ferrocarril-carretera, pues ésta no surgió pensando en complementar a aquél. En segundo lugar, y aunque faltan estudios sobre el tema, el transporte automotor contó con la ventaja de no tener que hacer frente a gastos de construcción y mantenimiento de las autovías. Finalmente, la competencia de la carretera coincidió con la crisis del sistema económico que había dado origen al ferrocarril, lo que empeoró la depresión del tráfico y dificultó la remodelación de la infraestructura para mejorar el servicio.

En los años treinta, mejorar el servicio o cerrar las líneas parecían ser las alternativas posibles para el ferrocarril. No obstante, fue una tercera opción la que se impuso. Coincidiendo con los cambios que tras la crisis de 1930 se produjeron en la economía y en la política del país, el Estado modificó su actitud frente al ferrocarril. En 1936 decidió hacerse cargo del Gran Ferrocarril de Venezuela, que había dejado de operar, ${ }^{28}$ y en 1938 recuperó la administración del Santa Bárbara-El Vigía. Desde ese momento, tres líneas de actuación se superponen en el tiempo, a veces de forma contradictoria. Las nacionalizaciones continuaron a lo largo de los años cuarenta y no respondieron a una política preconcebida, sino a las dificultades de operación de las empresas. El cuadro 4 muestra cómo el Estado se hizo cargo de $458 \mathrm{kms}$. de vía entre 1938-46, el 51\% de la red en su momento de máxima extensión. Las únicas líneas no nacionalizadas fueron las de $\mathrm{La}$ Ceiba, el Bolívar y el Puerto Cabello-Valencia, que dejaron de prestar servicio en 1947, 1954 y 1957 respectivamente. Antes de que cerrasen estos dos últimos ya lo había hecho el La Guaira-Caracas (1951), el Central y el Santa Bárbara-El Vigía (1954). Entre 1957-66 sólo prestaban servicio el Gran Ferrocarril de Venezuela y el de Táchira.

La tercera línea de actuación tiene que ver con la mejora del servicio de la que hablamos anteriormente. Sus orígenes datan de 1938, cuando el Estado decidió llevar a cabo el tendido El Palito-Palmasola para conectar las vías del Bolívar y el Puerto Cabello-Valencia. Las obras concluyeron en 1942. El hecho de que su administración se cediese a los propietarios de estos dos últimos ferrocarriles muestra de nuevo la ambigüedad de la política ferroviaria; aún más cuando transcurridos cinco años el gobierno decidió no renovar el contrato y recuperar el control de la línea. ${ }^{29}$

28 Baez: "Recientes...”, pág. 450.

29 Ibídem, pág. 453 y BCPF, ene.-feb. 1948, pág. 122. 
CUADRO 4

NACIONALIZACIÓN Y CIERRE DE LÍNEAS

Año Kms. nacion. Kms. cerrados

\begin{tabular}{rrl}
\hline 1896 & 37 & 0 \\
1908 & 97 & 0 \\
1909 & 110 & 0 \\
1938 & 196 & 0 \\
1943 & 375 & 0 \\
1944 & 412 & 0
\end{tabular}

Año Kms. nacion. Kms. cerrados

\begin{tabular}{rrr}
\hline 1946 & 600 & 0 \\
1947 & 600 & 81 \\
1951 & 600 & 118 \\
1954 & 600 & 508 \\
1957 & 600 & 618 \\
1966 & 600 & 618
\end{tabular}

La política ferroviaria iniciada en los años treinta culminó en 1944 con la creación del Instituto Autónomo de Administración de los Ferrocarriles del Estado (IAAFE), cuyo objetivo fue racionalizar la administración de las líneas, hasta entonces sujeta al Régimen de Bienes Nacionales, que impedía una gestión autónoma al considerar los beneficios de explotación como bienes públicos. El IAAFE salvó los inconvenientes de esa disposición, pero no mejoró la situación económica, como tampoco lo hizo la publicación del Plan Ferroviario Nacional (PFN) en 1950. El plan, tan ambicioso como inviable, demostró comprender los problemas históricos del ferrocarril, pero olvidó que la respuesta ya había sido dada por la carretera. Proponía construir 4.250 kms., con un ancho $(1,435 \mathrm{~ms}$.) e infraestructura que permitiese desarrollar velocidades comerciales; pero tropezó con dificultades financieras y con la competencia de una red caminera más completa, menos costosa y con un recorrido paralelo al de las líneas propuestas. El PFN, por tanto, fue una solución anacrónica, tuvo como saldo el inicio de una serie de obras que no se terminaron, y la reconstrucción de 177 kms. entre Barquisimeto y Puerto Cabello, antiguos tramos de los ferrocarriles Puerto Cabello-Valencia, Bolívar y Puerto Cabello-Valencia, abiertos al tráfico en $1959 .{ }^{30}$

30 Sobre el IAAFE, ver BCPF, sep.-oct. 1954, pág. 76 y Baez: "Recientes...”, págs. 451-57. Sobre el PFN, R. Nones: "Plan Ferroviario Nacional en Venezuela", Selecciones del Railway Age, Caracas, mar. 1957, pág. 30; "Se construirán 4.250 kms. de vías férreas en Venezuela”, Selecciones..., Caracas, feb. 1957, pág. 31; "El Plan Ferroviario Nacional y su desarrollo", BCPF, sep.-oct. 1954; BID: El desarrollo..., pág. 331; “Sinopsis...”, pág. 70 y CEPAL: El transporte..., pág. 270. 
MaPa 3. Plan FERroviario NACiONAL

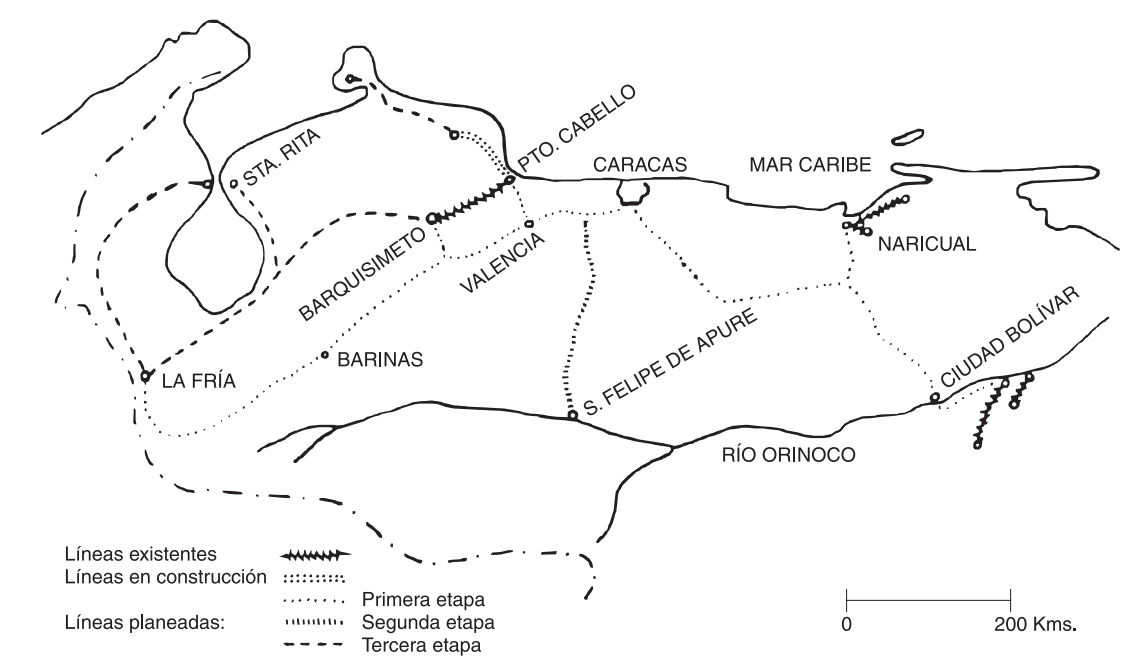

Fuente: Railways Directory..., 1970.

El tercero de los construidos en la región andina, el Gran Ferrocarril de La Ceiba tuvo características similares a las del Santa Bárbara-El Vigía y a las del ferrocarril de Táchira. Su razón de ser fue conectar los valles del suroeste del Maracaibo con el lago; tuvo el monopolio del transporte en la región debido a la ausencia de medios de comunicación en la zona; fue financiado por capital nacional y padeció la competencia de la carreta con más fuerza que otros ferrocarriles del país a causa de su aislamiento. Frente a las demás líneas andinas, su fecha de construcción (1888) le permitió gozar de la garantía del 7\%, aunque sólo para el tramo La Ceiba-Sabana de Mendoza, pues la concesión para prolongar sus vías hasta Trujillo la obtuvo en 1895 . Desde ese año no se produjeron nuevas variaciones en el trazado, con excepción de una pequeña ampliación hasta Varela en 1926. Su explotación fue muy rentable mientras contó con el citado monopolio del transporte. Esa misma razón explica también que fuese la línea más afectada por la competencia de la carretera y la que dejó de operar en fecha más temprana (1946)..$^{31}$

31 Ver Long: Railways..., pág. 373; Arcila: Historia..., págs. 255-56; Bloom: "Railways...", pág. 151 y $B C P F$, may.-jun. 1945, pág. 80, y ene.-feb. 1948, pág. 122. 
Siete de los doce ferrocarriles que comenzaron a construirse antes de 1892, fueron propiedad de capital extranjero y se situaron en la región centro-norte del país. El Carenero Rw., la más occidental de esas líneas, tuvo como razón de ser sacar al mar la producción del valle de Barlovento. La primera concesión para construirlo data de 1884, pero el tren no se inauguró hasta 1899. La empresa fue financiada por capital franco-venezolano y se mantuvo en manos privadas hasta su cierre en $1954 .^{32}$

La región centro-norte fue el núcleo de la expansión ferroviaria venezolana. Acaparó el interés estatal, que usó todo los medios disponibles para atraer al capital extranjero. Fue precisamente la liberalidad de las concesiones lo que impidió construir una red de transportes, a pesar de la existencia de un plan original para tender un ferrocarril Central que recorriese toda la región. A falta de un inversor capaz de llevarlo a cabo, el Estado lo dividió en varias concesiones, teniendo como resultado seis líneas independientes, con anchos y terminales diferentes. Además, hasta la apertura del tramo El Palito-Palmasola, el Bolívar estuvo aislado del resto; y hasta los años treinta, tras el inicio de las nacionalizaciones, el Estado no se planteó la necesidad de resolver algunos de esos problemas. Aun así, hubo que esperar a 1942-44 para la construcción del mencionado tendido El Palito-Palmasola y para la creación del IAAFE, y a 1950 para contar con un plan ferroviario, cuyas propuestas, según hemos visto, no fueron viables.

La política ferroviaria adoleció de un error de cálculo. Eliminada la garantía del $7 \%$ en 1882, el capital extranjero dejó de invertir. Al mismo tiempo, el traslado del cultivo cafetalero al área andina redujo el volumen de transporte en la región centro-norte. Las líneas más rentables, dedicadas al azúcar y al petróleo, también se concentraron alrededor del Maracaibo. ${ }^{33}$ En suma, desde fechas muy tempranas, los mismos factores que permitieron construir el ferrocarril se convirtieron en las causas de su ineficiencia. El único resultado de las distintas concesiones para construir el ferrocarril Central fue el tramo La Guaira-Caracas, abierto en 1883. En 1880, el norteamericano W.P. Pile obtuvo un contrato del

32 Ver Arcila: Historia..., págs. 249-52; BCPF, may.-jun. 1945, pág. 80; Long: Railways..., págs. 379-80 y Bloom: "Railway...”, pág. 152.

33 Aunque su estudio no es objeto de este trabajo, las obras de Long: Railways..., págs. 382-87; Arcila: Historia..., pág. 256; Jahn: Desarrollo..., pág. 20 y Halsey: The Railway..., pág. 107 contienen información sobre los mismos. 
Estado y éste inició las obras mientras él buscaba capital para financiarlas. En 1881, se creó en Londres La Guaira \& Caracas Rw. Co., y en 1883 el Estado le cedió los trabajos realizados. A pesar de las dificultades iniciales, fue una de las empresas de transporte mejor administradas del país. Hasta la década de 1930 obtuvo siempre beneficios. De hecho, fue una de los pocos ferrocarriles que mejoró sustancialmente su infraestructura, electrificándose en 1927. La competencia de la carretera, empero, debió ser especialmente desastrosa. En 1944 fue nacionalizado y en 1951 se cerró al tráfico. ${ }^{34}$

La construcción del Central de Venezuela fue la que tropezó con más dificultades. El inglés R. Pringle inició las obras el mismo año en que recibió la concesión (1885), pero quebró y el primer tramo no fue inaugurado hasta 1892. La coincidencia de su trazado con el del Gran Ferrocarril de Venezuela le obligó a renunciar en 1890 a llevar sus vías hasta Valencia. En 1905 obtuvo del Estado un contrato para extender las paralelas hasta Santa Lucía, donde llegó el primer tren en 1913, y en 1922 éstas se prolongaron hasta Ocumare. El retraso de las obras, lo perjudicado que salió del conflicto con el Gran Ferrocarril de Venezuela y el hecho de no contar con una terminal marítima propia impidieron conseguir buenos resultados económicos hasta la década de 1920. Soluciones parciales, como la electrificación del tramo Caracas-Petare en 1906 no aliviaron la situación. Eso explica que fuese el primer trayecto nacionalizado (1936) y que cuando el Estado decidió asumir su administración, la explotación se encontrase prácticamente abandonada debido a la competencia de la carretera. La línea se cerró al tráfico en $1957 .{ }^{35}$

El Gran Ferrocarril de Venezuela fue la línea más extensa. Sus 179 kms. unían las ciudades más importantes del país: Valencia y Caracas. De ahí también que fuese la única tendida en sentido Este-Oeste y no Norte-Sur. Compartió con el ferrocarril Central la característica de carecer de terminal portuaria, dependiendo de otros trazados para llegar al mar.

34 Ver Bloom: "Railway...", pág. 152; Arcila, Historia..., págs. 185-220; MOP: Centenario..., págs. 92-112; Zawisza, L.: Arquitectura y Obras Publicas en Venezuela. Siglo XX (2 vols.), Caracas, 1978, II, págs. 359-65; Long: Railways..., págs. 346-50; N. Veloz: Venezuela. Esbozo geográfico, recursos naturales, legislación y condiciones económicas, Caracas, 1966, pág. 351; Halsey: The Railway..., págs. 110-11 y Railway..., págs. 72-3 y BCPF, ene.-feb. 1948, pág. 122.

35 Ver Arcila: Historia..., págs. 236-41; Baez: "Recientes...", pág. 452; Halsey: Railway..., pág. 74 y The Railway..., pág. 115; Long: Railways..., pág. 358; Bloom: "Railways...”, pág. 154 y $B C P F$, may.-jun. 1945, pág. 80 . 
L.A. Müller, del grupo alemán Krupp, obtuvo en 1888 la concesión para iniciar las obras, junto con la propiedad del de Antimano, construido por el Estado en 1886, tras fracasar el contrato celebrado con Rivas \& Hernández en 1882. Finalmente, Krupp cedió sus derechos a la también alemana Grosse Venezuela Eichbahn-Gesellschaft, ${ }^{36}$ que asumió la dirección de la línea. Ya mencionamos los problemas surgidos por la coincidencia de su trazado con el del Central. Solucionados en 1890 y siendo la parte más favorecida, comenzaron las obras, y en 1893 se inauguró el ferrocarril. Su explotación fue bastante rentable, sobre todo en las décadas de 1910-1920. En 1924 fue vendido a la Compañía de los Ferrocarriles Sudamericanos (española), que mantuvo su propiedad hasta 1938, cuando se abandonó la explotación debido a la depresión del transporte y a la competencia de la carretera, y el Estado decidió nacionalizarlo. Debemos señalar, empero, que su relativamente largo recorrido le permitió afrontar dicha competencia mejor que otros ferrocarriles. Su línea fue la que cerró al tráfico más tarde (1966). ${ }^{37}$

Pile obtuvo la concesión para construir la línea Puerto Cabello-Valencia en 1880 junto con la de La Guaira-Caracas. Como en ese caso, el Estado inició las obras, pero Pile no pudo hacerse cargo de ellas finalmente y fueron entregadas a los ingleses W.J. Cutbill y U. de Lungo, que las acabaron en 1890. Hasta mediados de la década de 1920 la empresa fue bastante rentable. En 1924 fue adquirida por el ferrocarril Bolívar, a cuyos dueños había entregado el gobierno en 1896 la mayoría de las acciones del ferrocarril como pago de una subvención concedida en 1886. No obstante, su gestión se mantuvo independiente, pues los reiterados proyectos para unir ambas vías no se materializaron hasta que en 1942 el Estado inauguró el trayecto El Palito-Palmasola, que fue arrendado a los propietarios del Bolívar. La depresión de 1930, la competencia de la carretera y su escaso recorrido, problema que no palió la unión de su línea con la de este último, debido a que ambos ferrocarriles tenían anchos distintos, ocasionaron una crisis que concluyó con el cierre de la línea en 1957. En 1959 el tramo El Palito-Puerto Cabello fue remo-

36 La concesión debió estar relacionada con el préstamo del Diskonto-Gesellschaft al Estado para saldar la deuda ferroviaria y rescatar la garantía del $7 \%$.

37 Ver BCPF, may.-jun. 1945, pág. 80; Arcila: Historia..., págs. 227-35; Long: Railway..., pág. 377; Veloz: Venezuela..., pág. 535; Bloom: "Railway...”, pág. 153; Baez: "Recientes...", págs. 453-59 y Halsey, Railway..., pág. 73. 
delado y se reabrió al tráfico como parte del de Barquisimeto-Puerto Cabello. ${ }^{38}$

La razón de ser del ferrocarril Bolívar fue el transporte del cobre de las minas de Aroa. Aunque los primeros proyectos datan de 1835, el tendido de la vía no comenzó hasta 1873, cuando la New Quebrada Co. recibió la concesión. En 1877 se inauguró el tramo Tucacas-Aroa, el primer ferrocarril de servicio público abierto en Venezuela. En 1891 el tren llegó hasta Barquisimeto y en 1916 se completó con el ramal San FelipePalmasola, adjudicado en 1913, tras varios contratos infructuosos, a la Quebrada Land \& Copper Co., creada en 1883 para unir las concesiones de las empresas minera y ferroviaria. Los años 1910-30 fueron los más rentables para la línea. Eso le permitió extender su recorrido y absorber la propiedad del trazado Puerto Cabello-Valencia. A la depresión del tráfico en los años treinta y a la competencia de la carretera, se unió en este caso la decadencia del puerto de Tucacas frente al de Puerto Cabello tras la apertura del tendido El Palito-Palmasola, problemas que condujeron el cierre de la línea en 1954. En 1959 se reabrió el tramo BarquisimetoPalmasola como parte del ferrocarril Barquisimeto-Puerto Cabello. ${ }^{39}$

Para terminar el estudio del marco institucional, debemos hacer referencia al capital invertido en los ferrocarriles. El cuadro 5 reúne los datos disponibles. Los rasgos más destacados de ese capital ya han sido mencionados. Las inversiones extranjeras se concentraron en la región centro-norte y procedieron principalmente de Gran Bretaña, lo que se explica en función de las fechas de construcción de las líneas. ${ }^{40}$ Aunque se retiraron pronto de las empresas, hubo intereses franceses, junto con capital nacional, en las líneas de la región andina; un grupo norteamericano construyó el trayecto La Vela-Coro y otro alemán el Gran Ferrocarril de Venezuela, que en 1924 fue adquirido por una firma española. También hubo capital holandés durante un breve período de tiempo en el de Carenero.

38 Zawisza: Arquitectura..., pág. 2337; BCPF, ene.-feb. 1948, pág. 122; Arcila: Historia..., pág. 222; Veloz: Venezuela..., pág. 532; Bloom, "Railway...”, pág. 152; Halsey: Railway..., pág. 74 y The Railway..., pág. 113 y Long: Railways..., pág. 372.

39 Ver Arcila: Historia..., págs. 242-49; Long: Railway..., págs. 364-65; Halsey: Railway..., pág. 109 y The Railway..., págs. 74-5; Bloom: "Railways...”, pág. 151 y BCPF, may.-jun. 1945, págs. 79-80, y ene.-feb. 1948, pág. 122.

40 Por lo general, el capital británico fue el primero en invertir en la construcción ferroviaria en América Latina. Sólo desde finales del siglo XIX, el capital norteamericano empezó a sustituir a aquél en el sector. En Venezuela la construcción de líneas se detuvo antes de que se produjese esta transición. 


\section{CUADRO 5}

LÍNEAS PÚBLICAS Y PRIVADAS. ORIGEN DEL CAPITAL FERROVIARIO

\begin{tabular}{|c|c|c|c|c|c|c|c|c|c|c|c|}
\hline \multirow[b]{2}{*}{$A \tilde{n} o$} & \multirow{2}{*}{$\begin{array}{c}\text { Kms. } \\
\text { Red }\end{array}$} & \multirow{2}{*}{$\begin{array}{l}\text { Núm. } \\
\text { cías. }\end{array}$} & \multicolumn{3}{|c|}{ Nacional } & \multicolumn{3}{|c|}{ Británico } & \multicolumn{3}{|c|}{ Otras naciones* } \\
\hline & & & $N .^{o}$ & kms. & $\%$ & $N .^{o}$ & kms. & $\%$ & $N .^{o}$ & kms. & $\%$ \\
\hline 1880 & 68 & 1 & 0 & 0 & 0 & 1 & 68 & 100 & 0 & 0 & 0 \\
\hline 1890 & 235 & 5 & 0 & 0 & 0 & 4 & 181 & 77 & 1 & 54 & 23 \\
\hline 1900 & 818 & 11 & 6 & 352 & 43 & 4 & 287 & 35 & 1 & 179 & 22 \\
\hline 1910 & 818 & 10 & 5 & 352 & 43 & 4 & 287 & 35 & 1 & 179 & 22 \\
\hline 1920 & 869 & 10 & 5 & 358 & 41 & 4 & 332 & 38 & 1 & 179 & 21 \\
\hline 1930 & 912 & 10 & 5 & 378 & 41 & 4 & 355 & 39 & 1 & 179 & 20 \\
\hline 1940 & 912 & 9 & 5 & 464 & 51 & 3 & 269 & 29 & 1 & 179 & 20 \\
\hline 1950 & 886 & 4 & 2 & 654 & 74 & 2 & 232 & 26 & 0 & 0 & 0 \\
\hline 1960 & 502 & 1 & 1 & 502 & 100 & 0 & 0 & 0 & 0 & 0 & 0 \\
\hline 1970 & 177 & 1 & 1 & 177 & 100 & 0 & 0 & 0 & 0 & 0 & 0 \\
\hline
\end{tabular}

* 1890, ferrocarriles de capital francés; 1900-20, alemán y 1930-40, español.

La segunda característica del capital ferroviario fue que el capital nacional, a diferencia del extranjero, se concentró en las líneas de la región andina, no gozó del apoyo fiscal y tuvo que abonar al Estado el 5\% de sus ganancias, lo que causó dificultades financieras en todas las empresas. La intervención estatal en la construcción y explotación de los ferrocarriles también fue considerable. Entre 1870-1910 inició las obras en tres de ellos, participó en la propiedad de dos y asumió la de otros tres tras ser abandonados por sus dueños. En suma, se puede decir que el Estado llenó el vacío dejado por la iniciativa privada, afirmación que también es válida para explicar las nacionalizaciones a partir de los años treinta, justificadas por el abandono de las líneas, no por la existencia de un plan de consolidación ferroviaria. Finalmente, la política del gobierno desde los años cuarenta procuró la remodelación de algunos tramos y cerró paulatinamente los menos rentables, articulando un plan nacional que, como ya dijimos, tuvo como único resultado la reconstrucción de la línea Barquisimeto-Puerto Cabello, el único ferrocarril de servicio público venezolano que permanece abierto al tráfico.

Las fuentes consultadas no informan sobre el monto de las inversiones, pero Jahn ha calculado que el coste medio de las líneas en 1900 fue de 226.165 bols. $/ \mathrm{km} .{ }^{41}$ dato muy interesante, pues en ese año estaba construi-

41 Jahn: Desarrollo..., pág. 20. 
do el $80 \%$ del kilometraje, lo que permite estimar un desembolso total de 185.000.000 bols. El capital extranjero invirtió cerca de 105 millones (57\%) [un 62\% procedió de Gran Bretaña]; el nacional unos 80 (43\%), de los cuales, 9 fueron aportados por el Estado. Calculamos, sin embargo, que la contribución de este último se cifró unos 61 millones (el 33\% de la inversión total en el sector): entregó a manos privadas tramos de vía por valor de 10 millones, otros 25 en concepto de la garantía del 7\%, ${ }^{42}$ y 17 a cambio de la propiedad del ferrocarril La Vela-Coro y del Santa BárbaraEl Vigía, lo que eleva la participación del capital nacional al 68\%.

\section{Desarrollo de la red ferroviaria. Infraestructura y equipos de transporte}

El desarrollo de la red ferroviaria venezolana respondió al de los factores históricos e institucionales. El 82\% del kilometraje se construyó entre 1881-85, momento que coincidió con el período de relativa estabilidad política y económica del gobierno de Guzmán Blanco. El auge constructivo de finales de siglo contrasta con la situación posterior. Las medidas tomadas por Crespo para paliar el déficit financiero causado por la política ferroviaria paralizaron las construcciones. Entre 1885-1942 sólo se inauguraron $171 \mathrm{kms}$., y en casi todos los casos se trató de ampliaciones de las líneas abiertas en 1881-85, pues desde ese último año sólo se tendieron dos nuevos ferrocarriles: La Vela-Coro y El Palito-Palmasola. A las razones citadas para la paralización de las construcciones hay que añadir el cambio que observamos en la política estatal a partir de 1910, la crisis del sector externo y la depresión de 1930. Tras ella no hubo modificaciones en la extensión de la red hasta finales de los años cuarenta, cuando comenzaron a cerrar las líneas con la misma rapidez con que fueron tendidas, quedando abierto al tráfico solamente la de Barquisimeto-Puerto Cabello.

Las fuentes consultadas apenas aportan datos sobre el resto de la infraestructura viaria. Veloz dice que en 1902 había en el país $842 \mathrm{kms}$. de ferrocarril, incluyendo tranvías y líneas industriales, 105 estaciones y 109 túneles y 523 viaductos, de los que 86 y 212 pertenecían al Gran Ferrocarril de Venezuela; es decir, una obra de ingeniería por cada 1,3 kms. y una estación por cada 8. Hay que anotar también que el tendido de las vías no pre-

42 MOP: Centenario..., págs. 166-67 y Jahn: Desarrollo..., pág. 20. 


\section{CUADRO 6}

CUADRO KILOMÉTRICO DE LAS EMPRESAS FERROVIARIAS VENEZOLANAS*

\begin{tabular}{|c|c|c|c|c|c|c|c|c|c|c|c|c|c|c|}
\hline Años & $F B$ & $G C$ & $F C$ & $C R$ & $P V$ & $S V$ & $G F$ & $F N$ & $G F T$ & $L C$ & $F V$ & $V C$ & $P P$ & Total \\
\hline 1877 & 68 & & & & & & & & & & & & & 68 \\
\hline 1883 & 68 & 37 & & & & & & & & & & & & 105 \\
\hline 1886 & 68 & 37 & 10 & & & & & & & & & & & 115 \\
\hline 1888 & 68 & 37 & 17 & & & & & & & & & & & 122 \\
\hline 1889 & 68 & 37 & 17 & 54 & & & & & & & & & & 176 \\
\hline 1890 & 68 & 37 & 21 & 54 & 55 & & & & & & & & & 235 \\
\hline 1891 & 155 & 37 & 36 & 54 & 55 & 60 & & & & & & & & 397 \\
\hline 1892 & 155 & 37 & 40 & 54 & 55 & 60 & $* *$ & & & & & & & 401 \\
\hline 1893 & 155 & 37 & 40 & 54 & 55 & 60 & 179 & 37 & & & & & & 617 \\
\hline 1895 & 155 & 37 & 40 & 54 & 55 & 60 & 179 & 37 & 105 & 74 & & & & 796 \\
\hline 1896 & 155 & 37 & 40 & 54 & 55 & 60 & 179 & $F V$ & 105 & 74 & 37 & & & 796 \\
\hline 1897 & 155 & 37 & 40 & 54 & 55 & 60 & 179 & & 105 & 74 & 37 & 13 & & 809 \\
\hline 1898 & 155 & 37 & 40 & 54 & 55 & 60 & 179 & & 114 & 74 & 37 & 13 & & 818 \\
\hline 1908 & 155 & 37 & 40 & 54 & 55 & 60 & 179 & & 114 & 74 & 37 & 13 & & 818 \\
\hline 1909 & 155 & 37 & 40 & 54 & 55 & 60 & 179 & & 114 & 74 & 50 & $F V$ & & 818 \\
\hline 1911 & 155 & 37 & 55 & 54 & 55 & 60 & 179 & & 114 & 74 & 50 & & & 833 \\
\hline 1912 & 155 & 37 & 58 & 54 & 55 & 60 & 179 & & 114 & 74 & 50 & & & 836 \\
\hline 1913 & 155 & 37 & 63 & 54 & 55 & 60 & 179 & & 120 & 74 & 50 & & & 847 \\
\hline 1916 & 177 & 37 & 63 & 54 & 55 & 60 & 179 & & 120 & 74 & 50 & & & 869 \\
\hline 1922 & 177 & 37 & 86 & 54 & 55 & 60 & 179 & & 120 & 74 & 50 & & & 892 \\
\hline 1925 & 177 & 37 & 86 & 54 & 55 & 60 & 179 & & 120 & 81 & 50 & & & 899 \\
\hline 1926 & 177 & 37 & 86 & 54 & 55 & 60 & 179 & & 133 & 81 & 50 & & & 912 \\
\hline 1938 & 177 & 37 & $F C$ & 54 & 55 & $F V$ & 179 & & 133 & 81 & 196 & & & 912 \\
\hline 1942 & 177 & 37 & & 54 & 55 & & 179 & & 133 & 81 & 196 & & & 967 \\
\hline 1944 & 177 & $F V$ & & 54 & 55 & & 179 & & 133 & 81 & 233 & & 55 & 967 \\
\hline 1945 & 177 & & & 54 & 55 & & $F V$ & & 133 & 81 & 412 & & 55 & 967 \\
\hline 1946 & 177 & & & 54 & 55 & & & & $F V$ & 81 & 545 & & 55 & 967 \\
\hline 1947 & 177 & & & 54 & 55 & & & & & 0 & 600 & & $F V$ & 886 \\
\hline 1951 & 177 & \# & & 54 & 55 & @ & & & & & 526 & & & 812 \\
\hline 1954 & 0 & & \# & 0 & 55 & & \# & & & & 380 & & & 435 \\
\hline 1957 & & & & & 0 & & & & & & 325 & & & 325 \\
\hline 1959 & & & & & & & & & & & 502 & & & 502 \\
\hline 1966 & & & & \# & \# & & & & & & 177 & @ & \# & 177 \\
\hline 1970 & & & & & & & & & & & 177 & & & 177 \\
\hline 1987 & & & & & & & & & & & 177 & & & 177 \\
\hline
\end{tabular}

* FB: Fc. Bolívar; GC: La Guaira-Caracas; FC: Carenero; CR: Central; PV: Puerto CabelloValencia; SV: Santa Bárbara-El Vigía; GF: Gran Fc. de Venezuela (incluye el Antimano); FN: Naricual; GFT: Gran Fc. de Táchira; LC: Gran Fc. de La Ceiba (incluye el de Trujillo); FV: Ferrocarriles administrados por el Estado; VC: La Vela-Coro; PP: El Palito-Palmasola. El nombre en cursiva de un ferrocarril tras la serie kilométrica de otros indica que en ese año, la propiedad del mismo pasó al primero. \# Fecha de cierre de las distintas líneas. Antimano.

** Antes de esa fecha estaban construidos algunos kilómetros correspondientes al Fc.

@ Ignoramos fecha de cierre. En el caso del Naricual, cerró su línea al tráfico a principios de los años cincuenta. Se reabrió en 1959 para el transporte sólo minero. 
sentó grandes problemas técnicos, si exceptuamos los ocasionados por las frecuentes inundaciones en la región centro-norte durante la estación lluviosa. Lo más relevante que destaca la información sobre la infraestructura son las diferentes soluciones empleadas por cada empresa en el trazado de sus paralelas ${ }^{43}$ especialmente en el ancho de la trocha que, como muestra el cuadro 7 , ni siquiera respondió a razones como la región ferroviaria o el año de construcción.

\section{CuAdro 7}

ANCHOS DE VÍA DE LOS FERROCARRILES VENEZOLANOS

\begin{tabular}{|c|c|c|c|c|c|}
\hline Ancho & Kms. & $\%$ & Ferrocarril & Año constr. & Región \\
\hline 0,91 & 186 & 16 & $\begin{array}{l}\text { La Guaira-Caracas } \\
\text { Carenero } \\
\text { La Vela-Coro } \\
\text { Gran Fc de La Ceiba }\end{array}$ & $\begin{array}{l}1893 \\
1889 \\
1897 \\
1895\end{array}$ & $\begin{array}{l}\text { Centro-norte } \\
\text { Nororiental } \\
\text { Noroccidental } \\
\text { Oriental }\end{array}$ \\
\hline 1,06 & 568 & 50 & $\begin{array}{l}\text { Pto. Cabello-Valencia } \\
\text { El Palito-Palmasola } \\
\text { Gran Fc de Venezuela } \\
\text { Central de Venezuela } \\
\text { Sta. Bárbara-El Vigía } \\
\text { Gran Fc de Táchira }\end{array}$ & $\begin{array}{l}1890 \\
1942 \\
1893 \\
1892 \\
1891 \\
1895\end{array}$ & $\begin{array}{l}\text { Centro-norte } \\
\text { Centro-norte } \\
\text { Centro-norte } \\
\text { Centro-norte } \\
\text { Oriental } \\
\text { Oriental }\end{array}$ \\
\hline 1,45 & 391 & 34 & $\begin{array}{l}\text { Bolívar } \\
\text { Naricual } \\
\text { Barquisimeto-Pto. Cabello }\end{array}$ & $\begin{array}{l}1877 \\
1893 \\
1959\end{array}$ & $\begin{array}{l}\text { Centro-norte } \\
\text { Nororiental } \\
\text { Centro-norte }\end{array}$ \\
\hline
\end{tabular}

El cuadro 8 contiene la información disponible sobre los equipos de transporte. Aunque no tenemos datos anteriores a 1938, parece que la mayoría de los equipos fue adquirida en las últimas décadas del siglo XIX, cuando se inauguraron las líneas. Seguramente, entre esos años y la década de 1930 no hubo grandes variaciones en el número de unidades de tracción y remolque. Desde 1938 la evolución absoluta y relativa de las cifras, como cabía esperar tras el estudio de otras variables, muestra una reducción

43 Veloz: Venezuela..., pág. 531. Para más detalles sobre la infraestructura, ver JWR (1950/51$1981 / 82)$. 
progresiva de la cantidad de locomotoras y vagones debido a la crisis del sector exportador y a la competencia de la carretera. La disminución del número de automotores y coches de viajeros comenzó algo después, posiblemente al final de la década de 1940, cuando empezó a notarse también el efecto del cierre de las líneas. Finalmente, en los años setenta, los datos (referidos únicamente al ferrocarril Barquisimeto-Puerto Cabello) muestran una ligera tendencia al alza, coherente con lo que se aprecia en los indicadores del transporte, que veremos más adelante.

\section{CUADRO 8}

EQUIPOS DE TRANSPORTE*

\begin{tabular}{|c|c|c|c|c|c|c|c|c|c|c|c|c|c|}
\hline \multirow[b]{2}{*}{ Años } & \multicolumn{2}{|c|}{ Locomots. } & \multicolumn{2}{|c|}{ Automots. } & \multicolumn{2}{|c|}{ Coches } & \multicolumn{2}{|c|}{ Vagones } & \multirow[b]{2}{*}{ Total } & \multirow{2}{*}{$L / K$} & \multirow{2}{*}{$\begin{array}{l}C V \\
/ L\end{array}$} & \multirow{2}{*}{$\begin{array}{l}C V \\
/ K\end{array}$} & \multirow{2}{*}{$\begin{array}{l}C A \\
\% V\end{array}$} \\
\hline & $N .^{o}$ & $\%$ & $N .^{o}$ & $\%$ & $N .^{o}$ & $\%$ & $N .^{o}$ & $\%$ & & & & & \\
\hline & & & & & & & & & & & & 1,2 & 10,6 \\
\hline & 72 & & & & & 10 & & & & 7,4 & &, 9 & 20,1 \\
\hline & 36 & 4,7 & 33 & 4,3 & & & & 82,2 & 767 & 7,2 & 1,4 & 1,3 & 13,8 \\
\hline 965 & 21 & - & - & - & - & - & & - & - & 4,2 & - & - & - \\
\hline 969 & 9 & - & 19 & - & - & - & 249 & - & - & 5,1 & - & - & - \\
\hline 974 & 11 & 4,4 & 17 & 6,8 & 22 & & & 80,0 & 250 & 6,2 & 1,3 & 1,3 & 16,3 \\
\hline & 13 & 4, & 2 & 0 , & 1 & 4, & 272 & 91 & 299 & 7,3 & 1,6 & 1,7 & 4,8 \\
\hline & 1 & - & - & - & & - & - & - & - & 10,2 & - & - & - \\
\hline 1987 & 19 & - & - & - & 12 & - & - & - & - & 10,7 & - & - & - \\
\hline
\end{tabular}

* L/K: Locomotoras/kms. vía; CV/L: Coches+vagones/locomotoras; CV/K: Coches + vagones/kms. de vía; CA\%V: Coches y automotores como porcentaje de los vagones.

Respecto al tipo de tracción, sólo sabemos que originalmente los ferrocarriles utilizaron locomotoras a vapor y que las únicas modificaciones importantes fueron la electrificación en 1906 del tramo Caracas-Petare del ferrocarril Central y de la línea La Guaira-Caracas en 1927. Sabemos también que tras la reapertura en 1959 del Barquisimeto-Puerto Cabello se adquirieron nuevas locomotoras diesel y que éstas experimentaron un paulatino incremento de su potencia hasta llegar a $20.000 \mathrm{CV} /$ unidad en 1982. Con los vagones sucedió algo parecido: su capacidad descendió hasta principios de los ochenta, para luego aumentar y estabilizarse en torno a 10.500 tns./vagón. La capacidad de los coches de viajeros, finalmente, disminuyó hasta la década de 1950, estabilizándose en el decenio de 1980 en 1.300 por coche. ${ }^{44}$

44 Datos obtenidos de la información dispersa en las fuentes y bibliografía. 
Las fuentes consultadas no ofrecen información suficiente para dedicar un apartado al factor trabajo, por lo que comentamos aquí los datos disponibles. En la década de 1940 el sector ocupaba a unas 5.000 personas, cifra que se redujo hasta 2.672 en 1962 (5,3 operarios/km.). Desde ese año se observa una rápida disminución del número de trabajadores debido al cierre de las últimas líneas operativas (en 1980 trabajaban 1.332 personas en el ferrocarril Barquisimeto-Puerto Cabello), no así en el cociente operarios/km. de vía, que creció hasta 7,5 en 1980 debido al aumento del personal de servicios generales..$^{45}$ Eso debió ocasionar deficiencias que se resolvieron reduciendo la plantilla a 430 personas $(2,4 / \mathrm{km}$.) en $1986-87$.

\section{El transporte}

El cuadro 9 contiene promedios quinquenales absolutos y relativos del transporte ferroviario entre 1881-1990. Sus datos confirman lo que apuntaban otras variables para las que no teníamos tanta información: el número de viajeros creció de manera constante entre 1881-1930, salvo en el lapso 1901-05, debido a la crisis finisecular. Dicho crecimiento fue especialmente alto en los años 1886-95 y 1916-25, coincidiendo con la etapa de gran expansión constructiva y con la fase álgida del ciclo primario-exportador. Los cocientes viajeros $/ \mathrm{km}$. y habitante evolucionaron de forma similar. A partir de 1925, las tendencias se invirtieron. La finalización del ciclo alcista primario-exportador, la crisis de 1930 y la competencia de la carretera, explican la disminución en un 34\% del promedio de pasajeros en 1936-40 respecto de 1921-25. Aunque la Segunda Guerra Mundial supuso una mejora transitoria, la reducción del volumen de tráfico continuó en años sucesivos, agravada por el cierre de las líneas, llegando en 1956-60 a niveles similares a los del lapso 1886-90. La recuperación que se aprecia después de 1960 se debió a la apertura del trazado Barquisimeto-Puerto Cabello, pues en esa década se cerraron el Gran Ferrocarril de Venezuela y el de Táchira. Aun así, las magnitudes absolutas se mantuvieron estables hasta 1971-75. La distancia recorrida por usuario experimentó también un sensible aumento; no así los viajeros/habitante, debido al crecimiento demográfico de esos años. Finalmente, a partir de 1975, el tráfico sufrió una nueva crisis, estabilizándose en niveles muy bajos en la década de 1980.

$45 \operatorname{JWR}(1961 / 62-1981 / 82)$. 
ANTONIO SANTAMARÍA GARCÍA

\section{CUADRO 9}

TRANSPORTE DE VIAJEROS Y MERCANCÍAS*

\begin{tabular}{|c|c|c|c|c|c|c|c|c|c|}
\hline \multirow[b]{2}{*}{ Quinq. } & \multicolumn{3}{|c|}{ Viajeros } & \multicolumn{3}{|c|}{ Toneladas } & \multicolumn{2}{|c|}{ Kms. recorridos } & \multirow{2}{*}{$\begin{array}{c}\text { Viajeros/ } \\
\text { Tns. }\end{array}$} \\
\hline & Tot. & $/ H a b$. & $/ K m$. & Tot. & $/ H a b$. & $/ K m$. & Niaj. & $/ T n$. & \\
\hline $1881-85$ & 38 & 0,02 & 362 & 39 & 0,02 & 371 & - & - & 0,97 \\
\hline $1886-90$ & 135 & 0,06 & 978 & 80 & 0,04 & 449 & - & - & 1,68 \\
\hline $1891-95$ & 290 & 0,14 & 364 & 135 & 0,06 & 470 & - & - & 2,15 \\
\hline $1896-00$ & 439 & 0,20 & 537 & 146 & 0,06 & 178 & - & - & 3,01 \\
\hline $1901-05$ & 343 & 0,14 & 419 & 144 & 0,06 & 176 & - & - & 2,38 \\
\hline $1906-10$ & 440 & 0,18 & 538 & 165 & 0,07 & 202 & - & - & 2,67 \\
\hline $1911-15$ & 620 & 0,25 & 732 & 267 & 0,10 & 315 & - & - & 2,43 \\
\hline $1916-20$ & 1.206 & 0,47 & 1.388 & 347 & 0,13 & 399 & - & - & 3,48 \\
\hline $1921-25$ & 2.431 & 0,87 & 2.797 & 405 & 0,14 & 451 & - & - & 6,00 \\
\hline $1926-30$ & 2.445 & 0,83 & 2.681 & 469 & 0,16 & 514 & - & - & 5,21 \\
\hline $1931-35$ & 1.551 & 0,48 & 1.701 & 338 & 0,11 & 371 & - & - & 4,59 \\
\hline $1936-40$ & 839 & 0,23 & 920 & 404 & 0,11 & 443 & - & - & 2,08 \\
\hline $1941-45$ & 1.466 & 0,32 & 1.495 & 492 & 0,11 & 509 & - & - & 2,98 \\
\hline $1946-50$ & 811 & 0,16 & 915 & 400 & 0,07 & 451 & - & - & 2,02 \\
\hline $1951-55$ & 317 & 0,05 & 729 & 166 & 0,03 & 382 & - & - & 1,91 \\
\hline $1956-60$ & 151 & 0,02 & 301 & 89 & 0,02 & 177 & 92 & 132 & 1,70 \\
\hline $1961-65$ & 425 & 0,05 & 847 & 191 & 0,02 & 380 & 77 & 134 & 2,22 \\
\hline $1966-70$ & 438 & 0,04 & 2.475 & 131 & 0,01 & 740 & 93 & 121 & 3,28 \\
\hline $1971-75$ & 435 & 0,04 & 2.458 & 140 & 0,01 & 791 & 107 & 81 & 3,11 \\
\hline $1976-80$ & 314 & 0,02 & 1.774 & 161 & 0,01 & 910 & - & - & 1,95 \\
\hline $1981-85$ & 149 & 0,01 & 842 & 222 & 0,01 & 1.254 & - & - & 0,67 \\
\hline $1986-90$ & 142 & 0,01 & 802 & 114 & 0,01 & 814 & - & - & 1,25 \\
\hline
\end{tabular}

La evolución del tráfico de mercancías describe una curva similar, aunque algo más estable. La crisis finisecular, la depresión de 1930 y la competencia de la carretera tuvieron menos incidencia en este caso. Lo más llamativo es el estancamiento de las magnitudes absolutas y relativas entre 1921-50, como si los efectos positivos y negativos para la explotación ferroviaria se compensasen. La depresión del tráfico se manifestó súbitamente a partir de 1951-55. A los factores citados se unió en ese período el cierre de las líneas. La apertura del tramo Barquisimeto-Puerto Cabello se muestra también determinante en el 
volumen de carga: invirtió la tendencia a la baja de años precedentes, incrementando el transporte en un 115\% en 1961-65 respecto de 195559. Debemos señalar, asimismo, que el crecimiento observado en el primer lustro de los años ochenta se debió a la renovación del parque móvil que vimos en su momento, aunque no fue suficiente para evitar una nueva crisis en la segunda mitad de la década. Los indicadores relativos no aportan nada diferente, salvo el cociente viajeros/Tns., el cual indica que la vocación del tráfico fue esencialmente mercantil, aunque el servicio de pasajeros tuvo la entidad suficiente para convertirse en la razón primordial de la crisis del transporte desde la década de $1950 .{ }^{46}$ En lo que se refiere al tipo de mercancías acarreadas, los datos disponibles son poco explícitos. Sabemos que la mayor parte eran productos agrarios, sobre todo café, azúcar, maíz y leguminosas, destinados al consumo de las grandes ciudades y a exportación.

\section{La economía de los ferrocarriles}

El cuadro 10 contiene promedios quinquenales de los resultados económicos de los ferrocarriles. La evolución de sus datos es coherente con la del resto de las variables estudiadas. La tendencia alcista de ingresos y gastos fue la nota predominante del período 1881-1930 y el lapso 1911-25 aparece de nuevo como el más beneficioso para el sector. Desde entonces y hasta 1945 se invirtió la tendencia: ingresos, gastos y beneficios decrecieron, aunque el coeficiente de explotación siguió siendo positivo. ${ }^{47}$ La estabilidad de los volúmenes de carga que señalamos anteriormente explica este comportamiento. A partir de 1945, el negocio dejó de ser rentable. Ya dijimos que si la vocación del tráfico fue esencialmente mercantil, la reducción de número de viajeros fue clave en la depresión del sector. Los coeficientes se dispararon entre 1951-60. Luego, cierta recuperación del tráfico, el cierre de casi todas las líneas y algunas subvenciones estatales explican una leve mejora en estos últimos a

46 La razón viajeros/Tns. entre 1881-1990 fue en Venezuela 3,0; cociente muy elevado comparado con el de otros países de la región, como Nicaragua $(0,12)$, Cuba $(0,6)$ o República Dominicana $(0,6)$, Santamaría: "Los ferrocarriles de servicio público cubanos...", cuadro 7; "Los ferrocarriles de servicio público nicaragüenses...", cuadro 8 y "Los ferrocarriles dominicanos"..., cuadro 7.

47 El coeficiente de explotación es un deflactor de los resultados económicos. Es positivo siempre que su valor sea inferior a 100 . 
partir de 1976 y el brusco aumento de los ingresos y gastos. ${ }^{48}$ Finalmente, en el quinquenio 1986-90, todos los indicadores manifestaron un nuevo hundimiento, coherente con lo que vimos al analizar otras variables.

\section{CUADro 10}

RESULTADOS ECONÓMICOS (EN MILES DE BOLS.)*

\begin{tabular}{|c|c|c|c|c|c|c|c|c|c|}
\hline uinq. & Ingres. & Gastos & $R E$ & $C E$ & uinq. & Ingres. & Gastos & $R E$ & $C E$ \\
\hline & & & & & & & & & \\
\hline & & & & & & & & & 88,7 \\
\hline & & & & & & & & & 143,4 \\
\hline & & & & 70,7 & & & & & 99,2 \\
\hline & & & & & & & & & 74,9 \\
\hline & & & .715 & 69,9 & & & & & 410,2 \\
\hline & & & & 50,3 & & & & & 307,2 \\
\hline & & & & & & & & & 81,0 \\
\hline & 17.689 & & 6.49 & 63,3 & & & & & 153,7 \\
\hline $1926-30$ & 18.989 & 13.905 & 5.084 & 73,2 & & 37.000 & 38.000 & -1.000 & 102,7 \\
\hline $1931-35$ & 12.137 & 8.947 & 3.190 & 76,7 & $1886-90$ & 33.000 & 39.000 & -3.000 & 118,2 \\
\hline
\end{tabular}

* RE: Resultados económicos (ingresos-gastos); CE: Coeficiente de explotación (gastos/ingresos) x 100 .

Para terminar, en el cuadro 11 cotejamos los coeficientes de explotación del ferrocarril en Venezuela, Cuba, Nicaragua y República Dominicana, ${ }^{49}$ lo que confirma la hipótesis inicial acerca de la relación entre éste y el sector primario-exportador en la región en general y en Venezuela en particular. En el siglo XIX y primeras décadas del XX, dichos coeficientes fueron similares a los de Cuba (no tenemos datos para los otros casos). Entre 1930-50, sólo se asemejaron a los de la República Dominicana, donde las líneas existentes dejaron de operar en los años cincuenta y sesenta, y después de 1950 fueron sensiblemente peores que los de Cuba y Nicaragua.

48 La fuerte inflación que padeció la economía venezolana a partir de la crisis de finales de los setenta explica también lo elevado de las cifras.

49 Además de evitar el efecto de la inflación, el coeficiente permite comparaciones internacionales. Elegimos los casos de República Dominicana, Cuba y Nicaragua porque fueron los que estudiamos para el proyecto de la FFE. 


\section{CUADRO 11}

COEFICIENTES DE EXPLOTACIÓN COMPARADOS: VENEZUELA, CUBA, REPÚBLICA DOMINICANA Y NICARAGUA

Años

Antes 1900

1901-1929

1930-1950

Después 1950
Venezuela

Cuba

República Dominicana

61

61

77

87
93

109

Nicaragua

Fuentes: Cuadro 10 y Santamaría: "Los ferrocarriles de servicio público cubanos...”, cuadro 8; "Los ferrocarriles de servicio público nicaragüenses...", cuadro 10 y "Los ferrocarriles dominicanos"..., cuadro 8.

\section{Consideraciones finales}

Aunque la conclusión principal de este trabajo es la necesidad de realizar más estudios sobre el tema, el examen de la documentación consultada, especialmente estadística, permite ciertas consideraciones preliminares y algunas comparaciones. Las variables analizadas confirman la tesis inicial sobre la relación entre el tendido de los ferrocarriles, la construcción del Estado y la integración de la economía venezolana en el mercado mundial como productora de materias primas en las últimas décadas del siglo XIX. Esa relación fue común a casi todos los países latinoamericanos, pero parece que en ninguno de ellos se mostró tan determinante como en Venezuela. El ferrocarril nació para atender las necesidades de un sistema económico y socio-político en formación, jugó un papel fundamental dentro del mismo, pero no tuvo capacidad para convertirse en el motor del desarrollo y de la integración territorial y económica nacional.

Tras la Revolución Federal, Venezuela vivió un momento de relativa estabilidad que permitió construir las primeras líneas. Dichas líneas, empero, se ubicaron en la región más desarrollada del país (el centro-norte), uniendo los puertos con los núcleos productores del interior; desconectadas entre sí y reproduciendo el enfrentamiento entre las elites locales y la falta de integración y complementariedad entre las distintas áreas productivas. El crecimiento económico impulsado por el tren fue insuficiente para superar esos problemas. El tendido de las líneas fue posible gracias a la partici- 
pación de capital extranjero, pero sólo debido a que el Estado ofreció una garantía del 7\% sobre las inversiones, pues en el momento en que éste suspendió la garantía las construcciones se detuvieron. A ello hay que añadir que cuando aún no había terminado la expansión ferroviaria en el centronorte, el centro agrario cafetalero se trasladó a la región andina.

El contexto histórico en el que surgió el ferrocarril venezolano explica la concentración del período de construcción en las últimas décadas del siglo XIX, el hecho de que las líneas situadas fuera de la región centro-norte y tendidas después de la eliminación de la garantía estatal experimentasen dificultades financieras prácticamente desde que comenzaron a prestar servicio, así como que los mejores años para la explotación fuesen las primeras décadas del siglo XX, durante la fase álgida del ciclo primarioexportador. Tras esos años, coincidiendo con la finalización de dicho ciclo y con la depresión de 1930, el sector inició una crisis estructural que no pudo superar. Fue incapaz de adaptarse a los cambios que experimentó el país. La explotación petrolera sustituyó al café y a los productos agrarios para la exportación como motor de la economía. Una sociedad más compleja demandó reformas en el sistema político e indujo al Estado a intervenir en la economía para garantizar el incipiente desarrollo industrial y una mejor distribución de la renta procedente del petróleo. El ferrocarril no pudo responder a las necesidades de transporte que suscitaron esos cambios, ni resistir la competencia de unas carreteras, cuya construcción comenzó con el siglo, que consiguieron formar una red más integrada intra e interregionalmente, con un trazado paralelo al de las vías.

Desde finales de los años treinta se sucedieron dos rápidos procesos de nacionalización y cierre de las líneas. La nacionalización no respondió a una política de transportes; fue producto de la asunción por parte del Estado de las empresas cuando éstas dejaron de explotar los ferrocarriles. A pesar de la existencia de algunos planes de viabilidad en los años cuarenta y cincuenta, los defectos mencionados anteriormente no pudieron paliarse y las vías se fueron cerrando paulatinamente, quedando abierto al tráfico únicamente el ferrocarril Barquisimeto-Puerto Cabello, resultado de una remodelación de varias líneas de la región centro-norte. 